\title{
LA PRUEBA PERICIAL EN LOS DELITOS ECONÓMICOS. DE LA PERICIAL CONTABLE AL PERITO DE COMPLIANCE
}

\begin{abstract}
Ana María Neira Pena*
Resumen: El presente trabajo analiza la prueba pericial en los delitos económicos, cuya complejidad y creciente sofisticación demanda la intervención de técnicos o expertos que auxilien al juzgador en la reconstrucción de los hechos.

Junto con las tradicionales pruebas periciales económico-financieras, contables o consistentes en cuantificar el valor de un daño o en tasar ciertos bienes, surgen otras pericias, como las tributarias o las de compliance. Todas ellas presentan ciertos aspectos problemáticos comunes que serán objeto de tratamiento en este artículo. Concretamente, se abordará la formación requerida de los peritos, el alcance y objeto de la pericia económica, la naturaleza jurídico-procesal del peritaje económico, las garantías de imparcialidad de tales peritos, el momento procesal adecuado para aportar los dictámenes periciales, así como las reglas para su valoración judicial.
\end{abstract}

Recibido: julio 2019. Aceptado: julio 2020

* Profesora Ayudante Doctora. ORCID: https://orcid.org/0000-00026562-8208. Área de Derecho Procesal. Departamento de Derecho Público. Universidade da Coruña. Email: ana.neira@udc.es 
Palabras clave: prueba pericial, delitos económicos, pericial contable, pericial de compliance, iura novit curia, imparcialidad.

\title{
EXPERT EVIDENCE IN ECONOMIC CRIMES. FROM THE ACCOUNTING EXPERT TO THE COMPLIANCE EXPERT
}

\begin{abstract}
This paper addresses the expert opinion evidence in economic crimes which, being increasingly complex and sophisticated, demand the intervention of technicians or experts in order to help the judge in the reconstruction of the facts.

Along with the traditional economic-financial expert evidence, accounting expert evidence or expert opinions aimed at quantifying the value of damages or at assessing certain goods, other expert opinions arise, such as tax or compliance expert evidence. All of them present common problematic aspects, which addressed in this article. Specifically, the following matters will be discussed: the training required by the experts, the scope and purpose of the economic expertise, the legal-procedural nature of the economic expertise, the guarantees of impartiality of such experts, the appropriate procedural time to provide the expert opinions, as well as the rules for judicial evaluation of such evidence.
\end{abstract}

Key words: expert evidence, expert accountant, economic crimes, compliance, iura novit curia, impartiality

\section{Introducción}

El presente trabajo aborda la problemática de la prueba pericial en los delitos económicos. La delincuencia económica y, señaladamente, la denominada delincuencia de cuello blanco, a través de lo que paradigmáticamente se ha dado en llamar ingeniería financiera, ha alcanzado cotas de complejidad y sofisticación muy elevadas, que hacen necesario el conocimiento experto para desentrañar tales hechos delictivos.

Junto con las tradicionales pruebas periciales contables o aquellas consistentes en determinar el valor de un daño o de un determinado activo, surgen otro tipo de pericias encuadrables bajo la genérica denominación de periciales económicas. Dentro de estas, mención especial merece, 
por su novedad y su singularidad, la denominada pericial de compliance, que nace de la mano de la responsabilidad penal de las personas jurídicas, debido a la tecnificación de las normas relativas al cumplimiento normativo y a la prevención de delitos en el seno de las empresas.

Las cuestiones que, en relación con las periciales económicas, serán objeto de tratamiento en este trabajo son aquellas que, a mi juicio, resultan más problemáticas, controvertidas o carentes de una regulación legal adecuada. Así pues, en primer lugar, se tratará la cuestión relativa a la formación que tales peritos deben de poseer, haciendo hincapié en la necesidad de que exista una formación reglada y uniforme para estos profesionales y, sobre todo, en la importancia de contar con un registro público de profesionales del que se puedan valer los Juzgados y Tribunales a la hora de designarlos. En segundo lugar, se tratará de determinar el objeto de estas pericias, tomando en consideración la dificultad que, en ocasiones, se produce, para deslindar lo técnico y lo jurídico cuando se trata de apreciar un hecho económico con trascendencia jurídica. En cuarto lugar, se estudiará la distinta condición en que un experto en materia contable, económica o financiera puede ser llamado, según si ha tenido o no conocimiento extra-procesal de los hechos objeto del proceso. En quinto lugar, se abordará la garantía de imparcialidad de los funcionarios de la Agencia Tributaria, cuando son llamados a actuar en causas por delitos contra la Hacienda Pública, así como la posibilidad de recusar a los profesionales que prestan servicios en el ámbito privado ante la existencia de potenciales conflictos de interés que puedan condicionar su objetividad. En sexto lugar, se abordará el momento procesal adecuado, así como el momento preclusivo, para que las partes aporten los dictámenes periciales encargados extraprocesalmente. Y, por último, se tratará la cuestión de la valoración de la prueba pericial por el juzgador, así como la posibilidad de recurrir la sentencia con base en la inadecuada valoración de la prueba pericial por el Tribunal de instancia. 


\section{La relevancia de la prueba pericial en los delitos económi- cos y las deficiencias regulatorias de la LECrim}

La prueba pericial económica resulta, a día de hoy, absolutamente necesaria en la mayor parte de las causas por delitos contra el patrimonio y contra el orden socioeconómico, contra la Hacienda Pública o contra la Seguridad Social (arts. 305 a 310 bis CP). Algunas de las referidas figuras delictivas consisten, precisamente, en manipulaciones de la contabilidad, como ocurre, señaladamente, con los delitos fiscales (art. 305 CP), societarios (art. 290 CP) o concursales (art. $261 \mathrm{CP}$ ). Otras, como la estafa (art. $248 \mathrm{CP}$ ), la apropiación indebida (art. $253 \mathrm{CP}$ ), las insolvencias punibles (art. $259 \mathrm{CP}$ ) o la malversación de caudales públicos (art. $432 \mathrm{CP}$ ) incluyen en su descripción típica elementos como el perjuicio o el beneficio, en cuyo caso puede ser precisa una evaluación económica tanto para determinar si la conducta ha sido perjudicial o beneficiosa como para cuantificar el perjuicio o beneficio producido ${ }^{1}$.

Sea como fuere, resulta innegable que los asuntos relativos al denominado Derecho penal económico son campo abonado para la prueba pericial. Y ello por varios motivos. La primera razón tiene que ver con la insuficiencia de conocimientos específicos en materias de contenido económico, financiero, contable o tributario por parte de los Jueces y

1 Una lista de los delitos en los que la prueba pericial contable resulta esencial puede verse en BALAGUÉ DOMÉNECH, J. C.: La prueba pericial contable en los jurisdicciones civil, penal, contencioso-administrativa y laboral, $7^{\mathrm{a}}$ ed., Bosch, Madrid, 2018, pp. 157-168. El autor incluye en este listado los delitos contra el patrimonio y el orden socioeconómico, las defraudaciones (estafa, administración desleal y apropiación indebida), las insolvencias punibles, los daños, los delitos relativos a la propiedad intelectual e industrial, al mercado y a los consumidores, los delitos societarios, los de receptación y blanqueo de capitales, los de financiación ilegal de partidos políticos, así como los delitos contra la Hacienda Pública y la Seguridad Social, junto con las falsedades y malversación de caudales públicos. 
Magistrados $^{2}$. A esto hay que añadir la creciente profesionalización de la gran delincuencia económica, cada vez más compleja y refinada, que conduce a la necesidad de contar con expertos en materia económico-financiera para poder desentrañar y reconstruir los hechos relevantes para el proceso penal.

Además de los referidos, existe un tercer motivo que explica la relevancia de la prueba pericial en los delitos económicos, si cabe más reseñable por su carácter estructural, que tiene que ver con el modus operandi propio de estos delitos. Ocurre que, debido al modo en que estos hechos son normalmente perpetrados, en la mayor parte de los casos, no se cuenta con pruebas directas, porque no existe cuerpo del delito, vestigios, huellas o instrumentos, como acontece, habitualmente, en relación con otras figuras delictivas ${ }^{3}$. En este sentido, tal y como pone de manifiesto SAIz DíAz, normalmente, en las causas judiciales seguidas por delitos de naturaleza económica, negados los hechos por los investigados, la prueba testifical suele ser insuficiente o inexistente, por lo que la base probatoria fundamental es la documental y la pericial, ambas ligadas por consistir la segunda, la mayor parte de las veces, en el análisis e interpretación de fuentes de prueba documentales ${ }^{4}$.

2 Según MARCHENA GÓMEZ, M.: "De peritos, cuasiperitos y pseudoperitos", Poder Judicial, núm. 39, 1995, pp. 233-252, p. 244, "la preparación tradicional de Jueces y Fiscales (...) no se caracteriza, precisamente, por sus perfiles de vanguardia. Sectores jurídicos relacionados con el complejo mundo de la imposición fiscal, el mercado de valores o, simplemente, el derecho societario, no constituyen el eje central de la formación de Jueces y Fiscales, dándose la circunstancia de que la especialización en algunas de aquellas ramas jurídicas (...) permite el acceso cualificado a un orden jurisdiccional distinto del penal"; También critica esta escasa formación especializada SAIZ DÍAZ, C.: "La prueba pericial de contenido económico en el proceso penal", Revista del REFOR, núm. 9-10, 2004, pp. 23-29, p. 23.

3 SAIZ DÍAZ, C.: "La prueba pericial de contenido económico...", cit., p. 23.

4 SAIZ DÍAZ, C.: "La prueba pericial de contenido económico...", cit., p. 23. 
La relevancia que la prueba pericial económica presenta en la práctica de los Tribunales choca con la deficiente regulación de la LECrim, la cual, seguramente debido a su carácter decimonónico, regula la prueba pericial, en general, de forma insuficiente y anticuada. A nivel legislativo, poco o nada ha cambiado a este respecto, desde que en el año 1995, Marchena Gómez indicase que la regulación de la LECrim sobre la pericial deja traslucir una forma de concebir las posibles ofensas, propia del comportamiento delictivo de la época, señalando que tal marco normativo no puede "proporcionar cobertura normativa -aun forzada- a prácticas impuestas por nuevas formas de delincuencia", señaladamente, la denominada ingeniería financiera ${ }^{5}$.

Lo cierto es que, si se analiza la regulación legal de la prueba pericial, detallada y casuística en muchos aspectos, se observa como la misma gira en torno a un determinado modus operandi o a ciertas figuras delictivas muy distantes de las propias de la gran criminal económica o de cuello blanco. Concretamente, la LECrim prevé el reconocimiento pericial para el examen de los documentos públicos de cuya falsedad se sospeche, que pudieran estar en dependencias de las Administraciones Públicas (art. 335 LECrim). También para el reconocimiento de lugares, armas, efectos e instrumentos del delito (art. 336 LECrim), así como para determinar los medios empleados para hacer desaparecer el cuerpo del delito (art. 339 LECrim). Igualmente, regula con alto grado de detalle las funciones de los médicos forenses en casos de envenenamiento, heridas $\mathrm{u}$ otras lesiones, refiriéndose a la forma en que se practicarán el levantamiento del cadáver y las autopsias (arts. 343 a 355 LECrim), junto con la posibilidad de conducir operaciones de análisis químicos, incluyendo la determinación del perfil de ADN cuando resulte necesario (arts. 356 a 363 LECrim). Sin embargo, poco o nada dice so-

5 MARCHENA GÓMEZ, M.: "De peritos, cuasiperitos y pseudoperitos", cit., p. 243. 
bre la necesidad de conducir auditorías, periciales contables u otro tipo de pericias económico-financieras ${ }^{6}$.

Seguramente, la única alusión directa a una eventual pericial de contenido económico que se puede encontrar en la caduca y parcheada LECrim sea la referida a la estimación del valor de la cosa en casos de robo, hurto o estafa (art. 365 LECrim). Ni una sola alusión a otros tipos de delincuencia socioeconómica que, al contrario que los delitos patrimoniales tradicionales, ataca bienes jurídicos colectivos ${ }^{7}$, con el protagonismo indiscutible de las empresas como principales actores de esta criminalidad y con la manipulación contable como medio más habitual de perpetración de estas actuaciones.

\section{La prueba pericial económica en sentido amplio}

Según lo dispuesto en la LECrim "El Juez acordará el informe pericial cuando, para conocer o apreciar algún hecho o circunstancia importante en el sumario, fuesen necesarios o convenientes conocimientos científicos o artísticos" (art. 456) ${ }^{8}$.

6 Más precisa, quizás, pueda resultar la regulación contenida en la LECiv, supletoria de la LECrim, de más reciente aprobación, y por ello más moderna, especialmente, cuando regula la prueba pericial como instrumental o auxiliar de otros medios de prueba y, señaladamente, de la prueba documental. En este sentido, el art. 352 LECiv señala que "cuando sea necesario o conveniente para conocer el contenido o sentido de una prueba o para proceder a su más acertada valoración, podrán las partes aportar o proponer dictámenes periciales sobre otros medios de prueba", entre los que se encuentran documentos con datos, cifras y operaciones matemáticas llevadas a cabo con fines contables o de otra clase (art. 299.3 LECiv). Ahora bien, hay que tener en cuenta que las normas que regulan la iniciativa y las cargas probatorias en el proceso civil y en el proceso penal no son comunes y, en ocasiones, resultan, incluso, contradictorias entre sí.

7 Según MARTÍNEZ-BUJÁN PÉREZ, C.: Derecho penal económico, Iustel, Madrid, 2012, pp. 66, la afectación, aunque sea de modo mediato, a intereses socioeconómicos supraindividuales es el presupuesto imprescindible para integrar una figura delictiva en la categoría de Derecho penal económico.

8 Tal y como pone de manifiesto CÁMARA RUIZ, J.: "La prueba pericial contable en el proceso civil y penal", en AA.VV.: Pérez-Cruz Mar- 
Pues bien, cuando tales conocimientos técnicos especializados sean los propios de las ciencias económicas o empresariales se podrá razonablemente hablar de la prueba pericial económica.

La pericial económica sirve, en general, para la valoración de hechos de contenido económico cuya apreciación requiere de un conocimiento técnico y de un análisis objetivo. $\mathrm{Y}$, en este ámbito, se observa cómo, de la mano de la tecnificación de las ciencias económicas y empresariales, se ha ido ampliando, así mismo, el alcance objetivo de las pericias económicas, que han "dejado de ser la prueba contable para abarcar un gran abanico de cuestiones (...) tan diversas como la contabilidad, auditoría, valoración de empresas y activos, fiscalidad, estudios sectoriales, estudios de viabilidad, finanzas, marketing o seguros" $"$.

La prueba pericial económica puede ser entendida como un género dentro del cual se distinguen diversas subespecies en función del tipo de encargo objeto de la pericia. Claramente, se encuadrarían dentro de aquella, la prueba pe-

tín, A-J; Ferreiro Baamonde, X. (dirs.); Neira Pena, A. Ma (coord.) Los retos del Poder Judicial ante la sociedad globalizada. Actas del IV Congreso Gallego de Derecho Procesal (I Internacional), Servizo de Publicacións da Universidade da Coruña, A Coruña, 2012, pp. 51-72, p. 62, la LECrim, al contrario que la LECiv, no alude a los conocimientos técnicos, expresión seguramente más adecuada para las pericias objeto de este estudio, debiéndose esa omisión, seguramente, a que, siendo la ley procesal penal del año 1882, no contempla situaciones y avances inexistentes en la época.

9 CASTELLS LLAVINÉS, J.: "Dictámenes periciales sobre aspectos económicos. Metodología y ámbito", Diario La Ley, núm. 8119, 4 de julio de 2013, pp. 1-4, p. 1; En una línea similar, en AA.VV.: Alonso Alaya, M; Picazo González, P.; Malón Muñoz, A. (coords.) Memento experto. Perito Judicial. Francis Lefevbre, Madrid, 2017, p. 181, se indica que "la prueba pericial económica financiera es mucho más compleja que la pericial contable ya que se aparta de lo meramente contable y alcanza cuestiones de derecho económico, de microeconomía, tales como contratación, mercados, situación empresarial, valoración de empresas, etc. o, incluso, en determinados casos de macroeconomía". 
ricial contable, consistente en el análisis de la contabilidad y de otra documentación económica-financiera ${ }^{10}$, y la prueba pericial tributaria, relativa a la apreciación de hechos y actuaciones con trascendencia tributaria. Pero, no son esas las únicas, ya que, junto a ellas, habría que incluir dentro de las pericias económicas otras operaciones, como las destinadas a determinar en qué medida un acuerdo supone una restricción de la competencia o las preordenadas a valorar los daños y perjuicios derivados de una determinada decisión empresarial.

A los referidos ámbitos de actuación, habría aún que agregar uno, que se ha convertido en esencial como consecuencia de la introducción de la responsabilidad penal de las personas jurídicas en nuestro ordenamiento a través de la L.O. 5/2010, de 22 de junio, por la que se modificó el CP. Se trata del perito de compliance, que podrá ser llamado al proceso penal incoado frente a una persona jurídica para aportar sus conocimientos técnicos en relación con la idoneidad y efectividad del programa de cumplimiento normativo implementado por la entidad encausada para la prevención de los riesgos delictivos derivados de su actividad. En este sentido, se indica que "como cualquier sistema, bien sea considerado en su conjunto o bien tomando las diferentes partes o subconjuntos integrados por los procedimientos y actuaciones concretas que han de implantarse para su desarrollo, el compliance program es susceptible de ser sometido a la verificación de expertos", pudiendo abarcar, el dictamen a recabar de tales peritos, "desde la acreditación de la propia existencia o no del sistema, hasta la opinión acerca de la idoneidad o eficacia del mismo"11.

En el caso de la prueba pericial de compliance, tendente a evaluar la existencia, eficacia o idoneidad del modelo de

10 AA.VV.: Alonso Alaya, M; Picazo González, P.; Malón Muñoz, A. (coords.) Memento experto. Perito judicial, cit., p. 130, párrafo 1006.

11 AA.VV.: Alonso Alaya, M; Picazo González, P.; Malón Muñoz, A. (coords.) Memento experto. Perito judicial, cit., p. 351, párrafo 3180. 
organización y gestión implementado por una empresa para prevenir delitos, su clasificación como pericia económica se justificaría, a mi juicio, por tres motivos principales. Primeramente, porque deberá valorar hechos con contenido y trascendencia económica, supuestamente realizados en provecho de la organización. En segundo lugar, porque tales peritos deberán poseer conocimientos propios de las ciencias económicas y empresariales para su realización. Y, en tercer lugar, porque emplearán una metodología común a otras pericias económicas, señaladamente las técnicas de auditoría y de evaluación de riesgos ${ }^{12}$.

A pesar de la heterogeneidad que, aparentemente, podría darse entre las distintas especies de prueba pericial económica, todas ellas tienen en común ciertos aspectos. Así pues, entre otros, cabría destacar los siguientes rasgos compartidos. En primer lugar, todas se centran, primordialmente, en el análisis de información y/o documentación interna de una organización, la cual constituirá el objeto material de su pericia. Esto provoca que, para su adecuado desarrollo, requieran, en mayor o menor medida, bien de la colaboración de la entidad para acceder a esa documentación, bien de la intervención judicial para garantizar el acceso. En segundo lugar, como ya se anticipó, estas periciales se caracterizan

12 Ahora bien, parece claro que el alcance de una pericial de compliance será, en principio, más amplio que el de una pericial contable o tributaria, dado que los hechos que debe analizar y valorar el perito de compliance son mucho más complejos y heterogéneos. Piénsese en las diferentes operaciones periciales que tendrá que desarrollar el perito para certificar la idoneidad del modelo de gestión empresarial para prevenir la comisión de ilícitos penales o, en su caso, para detectar sus carencias. Entre otras cuestiones, el perito deberá analizar la posición institucional del compliance officer, esto es, si este gozaba de independencia y autonomía en relación con los administradores de la entidad, así como si contaba con recursos suficientes para desarrollar su función. También deberá evaluar la confiablidad del canal de denuncias, la alineación de las políticas de la empresa con su código de conducta, la adecuada formación de los empleados en lo que se refiere a la prevención delictiva y la eficacia de los mecanismos de control interno, entre otros aspectos relativos a la organización del ente investigado. 
porque requieren de conocimientos propios de las ciencias económicas y empresariales, tales como la contabilidad, la organización de empresas o la gestión financiera, entre otros. Y, por último, otra cuestión bastante común en este tipo de pericias radica en que, además del componente técnico, en el que reside su razón de ser y su justificación, en ocasiones presentan, así mismo, un cierto componente jurídico. Esta última característica nos enfrenta a un problema muy peculiar, que tiene que ver con la necesidad de compatibilizar el respeto del principio iura novit curia con el difícil deslinde que a veces se produce entre lo técnico y lo jurídico cuando se trata de informes periciales contables, tributarios o de compliance.

\section{La formación del perito económico}

A pesar de que, según la LECrim, los peritos pueden ser "titulares o no titulares" (art. 457), esto es, con o sin titulación oficial, en la pericial económica el perito deberá ser preferentemente titulado. Sólo para determinadas tasaciones o informes en materias no académicas o no sujetas a titulación oficial, como podría ser la tasación de joyas u obras de arte, será procedente acudir a un perito sin titulación ${ }^{13}$. En el resto de los casos, el perito habitualmente llamado a intervenir será el profesional que haya obtenido la titulación de economista, de titulado mercantil o de censor jurado de cuentas ${ }^{14}$. Dichas titulaciones son equivalentes entre sí a estos efectos, pero ninguna de ellas por sí sola otorga la habilitación como auditor de cuentas, por lo que no servirán cuando se requiera la intervención de este último profesional ${ }^{15}$.

13 SAIZ DÍAZ, C.: "La prueba pericial de contenido económico...”, cit., p. 25.

14 Según el Decreto de 26 de abril de 1977, núm. 871/77 (Presidencia), Estatuto Profesional de Economistas y Profesores y Peritos Mercantiles, todos los profesionales referidos (economistas, profesores y peritos mercantiles, intendentes mercantiles colegiados) pueden ejercer como peritos contables ante los Tribunales de Justicia

15 En este sentido, tal y como pone de manifiesto BALAGUÉ DOMÉNECH, J. C: La prueba pericial contable...cit., p. 37, "si las partes soli- 
"La intervención judicial del auditor de cuentas, como profesional contable que posee una habilitación especial derivada de su inscripción en el Registro Oficial de Auditores de Cuentas ( $R O A C$ ) dependiente del Instituto de Contabilidad y Auditoría de Cuentas (ICAC), será necesaria cuando la prueba a practicar se incluya entre las actuaciones que la Ley de Auditoría de Cuentas ( LAC) contempla específicamente como tales", por lo tanto, siempre que la actuación requerida sea la de auditoría de cuentas anuales o de otros estados financieros o documentos contables ${ }^{16}$. Por el contrario, cuando no se requiera una opinión de auditoría, sino la comprobación específica de hechos concretos, la emisión de certificaciones o la revisión de procedimientos con alcance limitado inferior al de la auditoría de cuentas, será suficiente con un economista, un titulado mercantil o un censor jurado de cuentas, aunque también podrá emitir el dictamen un auditor, el cual actuará sujeto, en todo caso, a la normativa reguladora de su actividad $^{17}$.

citan y el juez considera pertinente que la prueba pericial contable deba hacerla un titular mercantil o empresarial o economista, el dictamen que el perito habrá de emitir lo será en virtud del título profesional que le faculta y por el que haya sido designado. En tales casos no es necesario que el experto sea auditor, además de titular mercantil o empresarial o economista". Sin embargo, "si el carácter con el que es requerido el experto es en virtud de su condición de auditor, el perito habrá de ser, además, auditor inscrito en el ROAC". En cualquier caso, no cabe desconocer que, en una pericial contable, independientemente de cuál sea la formación del perito, las normas técnicas de auditoría para el análisis de la información, para su verificación y para la obtención de evidencia suficiente para formular conclusiones serán, seguramente, las pautas más útiles disponibles (AA.VV.: Alonso Alaya, M; Picazo González, P.; Malón Muñoz, A. (coords.) Memento experto. Perito judicial, cit., p. 141, párrafo 1066).

16 AA.VV.: Alonso Alaya, M; Picazo González, P.; Malón Muñoz, A. (coords.) Memento experto. Perito judicial, cit., p. 137, párrafo 1049.

17 AA.VV.: Alonso Alaya, M; Picazo González, P.; Malón Muñoz, A. (coords.) Memento experto. Perito judicial, cit., pp. 137-138, párrafos 1049-1050. 
En el caso específico de la pericial tributaria, hay que tener en cuenta que, muchas veces, el Juez contará con el parecer técnico de algún perito de la Administración Tributaria, quien ha podido tomar conocimiento de los hechos objeto del proceso en el previo procedimiento administrativo de comprobación o inspección o, por el contrario, ha podido ser designado ad hoc por el Juez encargado de la investigación penal para intervenir en el proceso. En cualquier caso, la pericial contradictoria que, en su caso, quiera hacer valer la defensa, idealmente deberá de ser realizada por un profesional con conocimientos análogos a los del perito de la Administración Tributaria, por lo tanto, ha de tratarse de un experto en la legislación fiscal, que conozca el sistema impositivo, así como los procedimientos de gestión tributaria ${ }^{18}$.

Cuando se aborda la formación del perito de compliance, el panorama se complica. A día de hoy, en España, no existe una titulación específica que acredite a alguien como experto en cumplimiento normativo. Y, lo que resulta, si cabe, más preocupante, no existe una normativa técnica unificada que regule la labor del encargado de cumplimiento o del auditor de cumplimiento ni que determine la formación mínima que tales profesionales deben de poseer. Consecuentemente, no existen, al menos hasta el momento, colegios de auditores de compliance, ya que ni siquiera contamos, por ahora, con un registro de profesionales cualificados para actuar en este ámbito.

Ante la falta de regulación, algunos autores proponen que sean los economistas o auditores de cuentas los que asuman el papel de auditores de cumplimiento ${ }^{19}$, mientras que otros propugnan, como profesionales llamados a realizar este tipo de pericias, a los expertos en valoración de riesgos o, en su caso, grupos de trabajo conformados por abogados y

18 BALAGUÉ DOMÉNECH, J. C.: La prueba pericial contable... cit., p. 168.

19 AA.VV.: Alonso Alaya, M; Picazo González, P.; Malón Muñoz, A. (coords.) Memento experto. Perito judicial, cit., p. 270, párrafo 2538. 
economistas ${ }^{20}$. A mi juicio, una doble formación en Derecho y Administración de empresas sería, seguramente, la ideal para asumir esta tarea, al menos, mientras las funciones de compliance officer, de certificador de compliance y de experto en compliance no se profesionalicen ${ }^{21}$.

Otra propuesta que podría ser interesante explorar es la realizada por MAgro SERveT ${ }^{22}$, quien defiende la conveniencia de crear un Registro público de expertos en complian$c e$, al que podrían acceder aquellos profesionales que hubiesen acreditado una formación adecuada y suficiente ante los, denominados por el autor, Institutos de Compliance. Estos Institutos podrían ser Universidades o Colegios profesionales debidamente habilitados por la Administración Pública competente para ofertar cursos formativos suficientes para acceder a esta acreditación, la cual, siempre en opinión del referido autor, podría tomar como ejemplo la formación exigida a los mediadores, consistente en una duración mínima de formación específica -100 horas de docencia efectiva en el caso de los mediadores- y unas determinadas horas de formación continua ${ }^{23}$.

20 MAGRO SERVET, V.: "Hacia la creación del registro de expertos en programas de compliance", Diario La Ley, núm. 9362, 2019, pp. 1-7, p. 7.

21 Tal y como se explica en NEIRA PENA, A. $\mathrm{M}^{\mathrm{a}}$.: La defensa penal de la persona jurídica. Representante defensivo, rebeldía, conformidad, compliance como objeto de prueba, Aranzadi, Navarra, 2018, p. 236, la contribución de peritos expertos en administración y dirección de empresas puede revelarse necesaria para reconstruir, sobre la base de las técnicas propias de la organización empresarial, la adecuación del sistema de delegaciones, la eficacia del sistema de evaluación y prevención de riesgos económico-financieros o, incluso, la adecuación de las medidas de prevención delictiva, en atención al grado de descentralización del ente o de la diversificación o deslocalización territorial de sus actividades.

22 MAGRO SERVET, V.: "Hacia la creación del registro de expertos", cit., pp. 1-7.

23 Desde luego, no estaría demás una regulación análoga a la establecida en el art. 11.2 de la Ley 5/2012, de 6 de julio, de mediación en asuntos civiles y mercantiles, según la cual "El mediador deberá estar en posesión de título oficial universitario o de formación profesional superior y con- 
Coincido con Magro Servet en que la existencia de un Registro Público serviría para acreditar, a través de su inscripción en el mismo, una preparación suficiente por parte de los profesionales del sector, dando confianza a las empresas que quisieran contratar sus servicios, evitando el intrusismo y permitiendo, además, que la Administración de Justicia contase con un listado de profesionales acreditados al que acudir cuando fuese necesario el nombramiento judicial de un perito de compliance.

En este punto, cabe recordar que, según el Tribunal Supremo 24 " "el núcleo básico de la responsabilidad de la persona jurídica, cuya acreditación por ello habrá de corresponder a la acusación" consiste en "la ausencia de las medidas de control adecuadas para la evitación de la comisión de delitos, que evidencien una voluntad seria de reforzar la virtualidad de la nor$m a$ ". Y que, tal y como indica el Alto Tribunal, si bien es cierto que, en la práctica, será la propia persona jurídica la que apoye su defensa en la acreditación de la real existencia de modelos de prevención adecuados, no puede sostenerse que, tal acreditación pese como obligación ineludible sobre la entidad acusada, ya que ello quebraría ciertos principios básicos de nuestro sistema de enjuiciamiento penal, tales como la prohibición de responsabilidad objetiva o la presunción de inocencia.

Por lo tanto, recayendo sobre la acusación la carga de acreditar la inexistencia o, en su caso, la ineficacia del modelo de prevención delictiva, cabe señalar que, más allá de cuál

tar con formación específica para ejercer la mediación, que se adquirirá mediante la realización de uno o varios cursos específicos impartidos por instituciones debidamente acreditadas, que tendrán validez para el ejercicio de la actividad mediadora en cualquier parte del territorio nacional". Esta regulación se concreta, a nivel reglamentario, en los arts. 3, 4, 5 y 6 del Real Decreto 980/2013, de 13 de diciembre, por el que se desarrollan determinados aspectos de la Ley 5/2012, de 6 de julio, de mediación en asuntos civiles y mercantiles.

24 STS (Sala $2^{\text {a }}$, Sección $1^{\text {a }}$ ) núm. 154/2016, de 29 de febrero (RJ 20161600), F. J. $8 .^{\circ}$ 
sea la estrategia seguida por la defensa, el Ministerio Fiscal, como acusación pública, puede necesitar de la asistencia pericial para acreditar la responsabilidad de la persona jurídica. Al mismo tiempo, es posible que el Juez considere necesario o conveniente acordar la práctica de una prueba pericial para determinar la idoneidad y la suficiencia de las medidas de prevención delictiva que la entidad afirme tener implementadas, dado que, sin duda, se tratará de una circunstancia apta para influir en la calificación de los hechos y en la culpabilidad de los delincuentes corporativos (cfr. art. 299 LECrim), cuya correcta apreciación podría requerir de ciertos conocimientos técnicos (art. 456 LECrim). De hecho, la importancia de conocer y apreciar esta circunstancia de forma correcta desde el inicio del proceso es tal que, incluso, puede resultar determinante de la decisión de sobreseimiento o de apertura del juicio oral. Por todo ello, resulta trascendental contar con una lista de profesionales, con una formación acreditada en la materia, a los que la acusación pública o el órgano judicial puedan acudir en caso de que lo consideren oportuno.

Por el momento, la falta de formación reglada específica del experto en compliance se ha intentado suplir con algunas iniciativas privadas, como la de la Asociación Española de Compliance (ASCOM) ${ }^{25}$, miembro de la Federación Internacional de Asociaciones de Compliance (IFCA), que está centrada en la profesionalización de la figura del compliance

25 En la web de ASCOM hay información disponible sobre el proceso de acreditación y examen para adquirir la habilitación para actuar como compliance officer y como perito experto en compliance, así como información sobre el modo de adquirir los materiales para su preparación, junto con el anuncio de ciertas actividades de formación específicas. Quizás, de mayor interés, podría ser el listado de nombres de personas certificadas en cada una de las convocatorias, que llevan celebrándose desde julio del año 2016, así como el listado de inscritos en el Registro de peritos expertos en compliance.Esta información está disponible en https://www.asociacioncompliance.com/ [último acceso 20/10/2020]. 
officer, a través de la certificación de estos profesionales, a los que se evalúa con la realización de un examen presencial de 75 preguntas tipo test, correspondientes a un conjunto de materiales teóricos estructurados en 20 módulos. A mi juicio, esta formación de corte teórico puede resultar insuficiente sino se completa con una formación práctica adecuada y con ciertas exigencias de formación continua. Pero, desde luego, lo más preocupante es que la ausencia de regulación deje en manos privadas la determinación de los requisitos precisos para desarrollar una labor como la del profesional de cumplimiento normativo. Sobre todo, si se toma en consideración que los programas de cumplimiento penal, a pesar de su naturaleza privada, revisten un valor cuasi-normativo y, en la medida en que persiguen el respeto de la legalidad y la neutralización de los riesgos penales, se ha llegado a afirmar, incluso, que asumen cierto carácter de orden público ${ }^{26}$.

\section{El objeto de la prueba pericial económica y los límites im- puestos por el principio iura novit curia}

Tradicionalmente, se ha dicho que los informes periciales no deben de contener valoraciones jurídicas. En este sentido, resulta ilustrativa la definición que ofrece DE LA Oliva Santos del perito, caracterizándolo, desde el punto de vista negativo, como "la persona experta en materia no jurídi$c a$, que elabora y trasmite al tribunal información especializada dirigida a permitir a éste el conocimiento y apreciación de hechos y circunstancias fácticas relevantes para el proceso" 27 .

26 GOÑI SEIN, J. L.: "Programas de cumplimiento empresarial (compliance programs): aspectos laborales", en AA.VV.: S. Mir Puig; M. Corcoy Bidasolo; V. Gómez Martín (dirs.); J. C. Hortal Ibarra; V. Valiente Ibáñez (coords.) Responsabilidad de la empresa y compliance. Programas de prevención, detección y reacción penal, B de F, Montevideo-Buenos Aires, 2014, pp. 367-419, pp. 368 y 383.

27 DE LA OLIVA SANTOS, A.; DÍEZ-PICAZO GIMÉNEZ, I.: Derecho Procesal Civil. El proceso de declaración, $3^{\mathrm{a}}$ ed., Centro de Estudios Ramón Areces S.A., Madrid, 2004, p. 397. 
Por su parte, MARChena Gómez señala, de forma crítica y contundente, que resulta "inaceptable una presencia funcional de tales expertos orientada hacia el asesoramiento jurídico en materias que, por su complejidad y vertiginoso ritmo de producción normativa, no estuvieran al alcance del juez" lo que, a su juicio, "implicaría (...) una intolerable adulteración del genuino sentido del informe pericial". El citado autor, añade, además, que "la cooperación de un tercero en la fijación del derecho aplicable (...) supondría una subrepticia intromisión en el ejercicio de funciones jurisdiccionales" ${ }^{28}$. En una línea similar, SAIZ DíAZ afirma que la prueba pericial no puede versar sobre la interpretación de normas jurídicas, aunque estas sean tan complejas o cambiantes como las tributarias ${ }^{29}$, por eso los informes periciales no deben de contener alegaciones relativas a la interpretación de normas jurídicas, no solo penales, sino tampoco fiscales o mercantiles, lo que no implica que tales cuerpos legales no puedan ser tomados en consideración a la hora de realizar los cálculos o valoraciones en que se basen sus conclusiones ${ }^{30}$.

No cabe duda de que el perito no es llamado para aportar conocimientos jurídicos al proceso, ni tampoco hechos, sino sus conocimientos técnicos necesarios para la correcta apreciación de los hechos ${ }^{31}$, siendo su función pronunciarse sobre datos cuya percepción escapa a las aptitudes comunes judiciales $^{32}$. Sin embargo, la separación entre los hechos, los conocimientos precisos para comprender tales hechos y la valoración técnica y jurídica de los mismos, en la práctica, no es siempre tan clara como podría parecer.

28 MARCHENA GÓMEZ, M.: "De peritos, cuasiperitos y pseudoperitos", cit., p. 245.

29 SAIZ DÍAZ, C.: "La prueba pericial de contenido económico...", cit., p. 24.

30 SAIZ DÍAZ, C.: "La prueba pericial de contenido económico...", cit., p. 28.

31 STC 33/1992, de 18 de marzo, F. J. $4^{\circ}$.

32 GIMENO SENDRA, V.: Derecho Procesal Civil, $4^{\circ}$ ed., Colex, Madrid, 2012, pp. 483-484. 
La dificultad de deslinde que se da entre lo técnico y lo jurídico se observa, claramente, en las pruebas periciales tributarias. Parece evidente que el Derecho Tributario, más allá de contener un componente técnico, no deja de ser Derecho. Lo mismo cabe decir del Derecho societario, de la normativa reguladora del mercado de valores o, incluso, del Plan General de Contabilidad, que no deja de ser una norma jurídica ${ }^{33}$, por más que tenga un contenido eminentemente técnico.

Así pues, por ejemplo, para calcular la cuota dejada de ingresar a la Hacienda Pública, además de principios contables y criterios técnicos de valoración y registro contable, es preciso también considerar la normativa tributaria, cuya aplicación puede requerir de la realización de interpretaciones de naturaleza jurídica. Piénsese, sin ir más lejos, que la determinación del hecho imponible requiere de la interpretación de una norma jurídica e implica subsumir unos determinados hechos en tal norma legal ${ }^{34}$, al igual que la selección del método adecuado para calcular la base imponible. Por lo tanto, hay que convenir con SAIz Díaz en que el hecho de que tales cuerpos normativos no puedan ni deban ser objeto de informe pericial, no implica que no puedan ser empleados por los peritos para la realización de las operaciones periciales y para alcanzar sus conclusiones ${ }^{35}$.

Esa confusión entre lo técnico y lo jurídico se observa, si cabe de forma aún más evidente, al abordar el objeto de la pericial de compliance. Piénsese que los requisitos que debe

33 Real Decreto 1514/2007, de 16 de noviembre, por el que se aprueba el Plan General de Contabilidad.

34 La Ley 58/2003, de 17 de diciembre, General Tributaria determina, en su artículo 20, que el hecho imponible "es el presupuesto fijado por la ley para configurar cada tributo y cuya realización origina el nacimiento de la obligación tributaria principal". En definitiva, de acuerdo con el referido precepto, el hecho imponible no es más que un hecho con trascendencia económico-tributaria, que viene determinado por una norma con rango de ley.

35 SAIZ DÍAZ, C.: "La prueba pericial de contenido económico...", cit., p. 29. 
de tener el modelo de organización y gestión de una empresa para que esta pueda lograr, a través de su implementación, la exoneración de responsabilidad por los delitos cometidos por sus miembros, aparecen referidos en el art. 31 bis 5 CP. Por su parte, las especificaciones técnicas de esta norma penal, susceptibles de certificación por los correspondientes organismos evaluadores, aparecen detalladas en el estándar UNE 19601:2017 Sistemas de gestión de compliance penal, elaborado en el seno de la Asociación Española de Normalización. En la introducción de la referida norma UNE 19601:2017 se alude, expresamente, al contenido de la ley penal, señalando que su articulado constituye un "marco de interpretación" que la norma técnica pretende desarrollar. Pues bien, en un contexto como el descrito, parece evidente que el certificado que acredite el cumplimiento de las especificaciones contenidas en la norma UNE ha de partir de la normativa penal, interpretándola, en caso de ser preciso.

La procedencia de las periciales económicas, tales como las contables o las de compliance, se justifica por la necesidad de contar con ciertos conocimientos técnicos, de los que los Jueces y Magistrados carecen, sin que sea posible impedir que tales peritos, en el desarrollo de sus pericias, usen e interpreten determinadas normas jurídicas aplicables al caso. En este sentido, tal y como afirma BALAGUÉ DoMÉNECH, aunque al experto corresponden la apreciación del hecho y al Juez la calificación del Derecho, "muchas veces los hechos económicos con trascendencia jurídica (...) se hallan tan estrechamente incardinados que resulta imposible su tratamiento por separado, lo que obliga a un tratamiento global" 36 . Ahora bien, a la hora de valorar los informes periciales, sí será necesario deslindar lo que es opinión técnica en sentido estricto y lo que cae dentro de la valoración jurídica, como luego se comentará.

36 BALAGUÉ DOMÉNECH, J. C.: La prueba pericial contable...cit., p. 196. 
Así pues, por ejemplo, la pericial contable requiere conocimiento experto de todo lo que concierne a los elementos que integran las cuentas anuales ${ }^{37}$, también sobre los principios contables ${ }^{38}$, sobre los criterios de valoración de los elementos integrantes de las cuentas ${ }^{39}$, así como sobre ciertas normas técnicas, como las de registro y valoración o las de elaboración de las cuentas anuales, entre otras. Las referidas normas son de indudable carácter técnico. Ahora bien, su aplicación o el análisis de la información contable puede requerir, además, realizar valoraciones jurídicas o cuasi-jurídicas para determinar, por ejemplo, si la reclasificación de un determinado riesgo resulta razonable o si un determinado ajuste contable tiene un respaldo suficiente, tanto en la normativa como en la información de mercado disponible, así como si un determinado hecho puede ser considerado de nuevo conocimiento o debió conocerse usando la debida diligencia. Igualmente, el perito contable puede pronunciarse sobre si la información de la memoria contable es suficientemente detallada y razonada o si, por el contrario, existe una carencia o insuficiencia de información, lo que encierra interpretación de conceptos técnicos y jurídicos indeterminados y, por lo tanto, necesitados de valoración técnica, pero también judicial.

Por su parte, la prueba pericial sobre compliance es adecuada y aun idónea para determinar la eficacia de un modelo de cumplimiento en orden a prevenir delitos de la naturaleza del cometido ${ }^{40}$. Se afirma, en este sentido, que, en

37 Esto es, el balance, la cuenta de pérdidas y ganancias, el estado de cambios en el patrimonio neto, el estado de flujos de efectivo y la memoria

38 Principios tales como el de empresa en funcionamiento, el de devengo, el de prudencia, el principio de importancia relativa o el de no compensación, entre otros

39 A modo de ejemplo, el coste histórico, el valor razonable, el valor neto realizable, el valor actual, el valor en uso, etc.

40 GASCÓN INCHAUSTI, F.: Proceso penal y persona jurídica, Marcial Pons, Madrid/Barcelona/Buenos Aires/Sao Paulo, 2012, p. 147; En la misma línea, GÓMEZ-JARA DÍEZ, C.: "La culpabilidad de la persona 
la medida en que el programa de cumplimiento tiene que reflejar el estado de la técnica de prevención de riesgos en el sector de que se trate, su eficacia debe ser acreditada en el proceso penal por medio de una pericial, si bien se tratará de una pericial peculiar, puesto que combinará elementos de contenido jurídico-penal y otros de corte más técnico ${ }^{41}$. Y es por ello que, en último término, será el Juez el que determine si, en el caso concreto, las medidas de prevención aplicadas fueron suficientes o no para determinar si la entidad contaba con una cultura de cumplimiento suficientemente robusta.

Desde el momento en que existen normas técnicas, como la referida UNE 19601:2017, que regulan cómo debe de gestionarse la función de cumplimiento normativo para que resulte auditable, la labor del perito de compliance resulta relevante para la determinación de si se han cumplido o no tales especificaciones normativas infra-legales. Sin embargo, el hecho de que lo que se verifique a través de esta pericial sea

jurídica” en M. Bajo Fernández; B. J. Feijoo Sánchez; C. Gómez-Jara Díez, Tratado de responsabilidad penal de las personas jurídicas. 2. ${ }^{\mathrm{a}}$ ed. Adaptado a la Ley $1 / 2105$, de 30 de marzo, por la que se modifica el Código Penal, Aranzadi, Navarra, 2016, pp. 143-219, p. 218, afirma que la presentación de periciales, realizadas por empresas especializadas, que aseveren la institucionalización efectiva de una cultura de cumplimiento de la legalidad en el momento de cometerse el delito, será, en ciertos casos, la vía idónea para excluir la responsabilidad de la persona jurídica; Por su parte, COCA VILA, I.: “Programas de cumplimiento como forma de autorregulación regulada?", en AA.VV.: J-M, Silva Sánchez (Dir.), R. Montaner Fernández (Coord.) Criminalidad de empresa y compliance. Prevención y reacciones corporativas, Atelier, Barcelona, 2013 , pp. 43-76, p. 63, advierte que, quienes valorarán la eficacia de los programas de cumplimiento, en último término, deberán ser los jueces, si bien tendrán que recurrir necesariamente a informes periciales de expertos independientes.

41 GALLEGO SOLER, J-I.: "Criminal compliance y proceso penal: reflexiones iniciales" en AA. VV., S. Mir Puig; M. Corcoy Bidasolo; V. Gómez Martín (dirs.); J. C. Hortal Ibarra; V. Valiente Ibáñez (coords.) Responsabilidad de la empresa y compliance. Programas de prevención, detección y reacción penal, B de F, Montevideo-Buenos Aires, 2014, pp. 195-229, p. 223. 
la eficacia de la organización para prevenir la comisión de ilícitos penales, le otorga, sin duda, un carácter particular, en tanto que el perito, en último término, deberá determinar si la entidad fue diligente en la prevención de delitos de acuerdo con los estándares del $\mathrm{CP}$, tal y como se concretan técnicamente en las normas que los desarrollan.

Las conclusiones que el perito de compliance podría alcanzar en su informe son susceptibles de clasificarse en varias categorías. Una primera, en la que el perito determine que no había programa de cumplimiento o que el existente era meramente cosmético, esto es, absolutamente inefectivo, por no haberse implementado de forma real en la organización. Una segunda opción sería que el perito, tras la realización de las oportunas operaciones periciales, entendiese que había un programa de cumplimiento, pero que este resultó insuficiente, ya por carecer de algunos de sus elementos esenciales, ya por haberse producido fallos en su implementación o en su funcionamiento determinantes de un control deficiente en relación con los riesgos normativos luego materializados. Y, por último, una tercera posibilidad, que pasaría por concluir, tras la realización de las oportunas operaciones periciales, que, siendo adecuadas y suficientes las medidas de control, la comisión del delito se debió, bien a la materialización de un riesgo imprevisible o de difícil previsión, bien a la elusión fraudulenta de los controles por parte del presunto autor de los hechos ${ }^{42}$.

Ahora bien, el perito deberá abstenerse de realizar juicios sobre la reprochabilidad de la conducta del acusado o

42 Cfr. AA.VV.: Alonso Alaya, M; Picazo González, P.; Malón Muñoz, A. (coords.) Memento experto. Perito judicial, cit., pp. 357-358, párrafos 3230-3240, donde se distinguen cuatro posibles conclusiones: a) Conducta delictiva imprevisible con la mejor técnica de análisis de riesgos; b) Negligencia o violación del deber de diligencia por parte de la entidad; c) Medidas cosméticas o inexistencia de facto del compliance; d) Elusión fraudulenta de las medidas por parte del sujeto que cometió el delito. 
valoraciones sobre su culpabilidad ${ }^{43}$. Esta afirmación, trasladada al ámbito de la responsabilidad penal de las personas jurídicas, implicaría que la pericial de compliance no debe de pronunciarse sobre si la entidad contaba o no con una cultura de cumplimiento, dado que la ausencia de la misma constituye, según el Tribunal Supremo, el núcleo del injusto de la responsabilidad del ente ${ }^{44} \mathrm{y}$, por lo tanto, su apreciación debe de corresponder, de forma exclusiva y excluyente, al juicio jurisdiccional.

De igual forma, el perito de compliance, una vez constatado el incumplimiento de los deberes de control, deberá abstener de calificarlo como jurídico-penalmente relevante o irrelevante, aunque sí parece posible que lo clasifique en función de su gravedad. Igualmente, no debería, en principio, pronunciarse sobre si, en el caso concreto, concurre una necesidad preventivo-especial que aconseje imponer penas restrictivas de derechos, aspectos normativos en los que el criterio técnico del perito, si bien puede nutrir la convicción judicial, no debe suplantarla ${ }^{45}$. Como cabe deducir de lo dicho hasta el momento, la línea entre lo que es objeto del informe pericial de compliance y lo que debe de quedar reservado a la apreciación judicial no siempre es nítida, estando a veces la clave, no tanto en lo que se dice, sino en cómo se dice y, sobre todo, en cómo se valora judicialmente.

En definitiva, una vez determinada la necesidad de contar con los conocimientos técnicos de auditores, expertos en contabilidad o expertos en compliance en el proceso penal, no es posible prohibir de forma absoluta el empleo de normas jurídicas en el desarrollo de sus pericias ni la incorpora-

43 BALAGUÉ DOMÉNECH, J. C.: La prueba pericial contable...cit., p. 196.

44 STS (Sala 2a , Sección $1^{\text {a }}$ ) núm. 154/2016, de 29 de febrero (RJ 2016\600), F. J. $8^{\circ}$.

45 NEIRA PENA, A. M ${ }^{\mathrm{a}}$. : La defensa penal de la persona jurídica...cit., pp. 236-237. 
ción de interpretaciones jurídicas en sus conclusiones. Ahora bien, a la hora de valorar el informe pericial sí será preciso que el Juez deslinde aquello que el perito aporta como técnico, lo cual constituye precisamente el objeto de su pericia, y aquellas otras afirmaciones o interpretaciones jurídicas que incorpora a su informe, respecto de las cuales el Juez podrá imponer siempre su mejor criterio, de acuerdo con el principio iura novit curia ${ }^{46}$.

\section{La naturaleza jurídico-procesal del peritaje económico}

En parte vinculado con el difícil deslinde que, en ocasiones, se produce entre el contenido técnico y jurídico de algunos informes periciales, se origina una cierta confusión en cuanto a la naturaleza de ciertas pericias, señaladamente cuando se trata de periciales encargadas a determinados entes públicos o a funcionarios públicos, designados por el Juez de instrucción, siendo tales periciales consideradas o incorporadas al proceso, no como fuentes de prueba, sino como instrumentos de auxilio judicial. En esta línea, la Exposición de Motivos de la LECiv alude a la "regulación decimonónica que reflejaba el no resuelto dilema acerca de la naturaleza de la actividad pericial, si medio de prueba o complemento o auxilio del juzgador" ${ }^{47}$.

La actual LECiv del año 2000 se decanta claramente por entender los dictámenes periciales como medios de

46 En este sentido, la STS (Sala 1 ${ }^{\text {a }}$ ) núm. 87/1994, de 10 febrero (RJ 1994|848) señala que "el Juez puede sustituir al perito cuando se considere suficientemente informado por sí para conocer o apreciar el objeto o la cuestión litigiosa que hubiera necesitado de la intervención de otra persona que tengas los conocimientos artísticos, científicos o prácticos requeridos por las circunstancias del caso" (F. J. $4^{\circ}$ ).

47 Las diferentes posturas doctrinales sobre la naturaleza jurídica del peritaje, calificándolo unos autores como auxiliares del juez y otros como medio de prueba, son recogidas en LÓPEZ-MUÑIZ GOÑI, M.: La prueba pericial. Guía práctica y jurisprudencia, Colex, Madrid, 2008, pp. $24-26$ 
prueba, por lo tanto, sometidos a las garantías propias de la contradicción y la libre valoración judicial. Y así deben de entenderse también los peritos designados judicialmente, incluso en la fase de instrucción de un proceso penal, dado que, normalmente, tales diligencias de investigación, a través de su ratificación en el plenario, pasan a erigirse en auténticos medios probatorios, con influencia en el juicio jurisdiccional, lo que hace obligado someterlos al tamiz de la contradicción.

Por ejemplo, si en una causa por delito contra la Hacienda Pública, el Juez quiere contar con el parecer técnico del inspector actuario que, en el desarrollo del procedimiento de comprobación tributaria ha detectado un posible delito, ha de designarlo como perito o, en su caso, como testigoperito, no pudiendo escucharlo simplemente en calidad de auxiliar del órgano judicial ${ }^{48}$. Su llamamiento como perito

48 Esta situación es criticada por MARCHENA GÓMEZ, M.: "De peritos, cuasiperitos y pseudoperitos", cit., pp. 243-346, quien los califica de pseudo-peritos, señalando que la intervención de ciertos cualificados funcionarios como auxiliares de los órganos judiciales no encuentra cobertura normativa en la LECrim, situación que, a su parecer, se agrava cuando tales técnicos son, en realidad, expertos en ciertas disciplinas jurídicas "que ni siquiera se presentan bajo el forzado camuflaje que pudiera proporcionar el sistema de designación de peritos o las garantías de contradicción que presiden la emisión de su informe". A juicio del autor, el art. 473.1 LOPJ según el cual "Podrán prestar servicios en la Administración de Justicia funcionarios de otras Administraciones que, con carácter ocasional o permanente, sean necesarios para auxiliarla en el desarrollo de actividades concretas (...) que requieran conocimientos técnicos o especializados", no puede servir de amparo para la utilización de técnicos en materia jurídica especializada; Sin embargo, en contra de este parecer, GAMO YAGÜE, R.: "Colaboración de la Agencia Estatal de Administración Tributaria con los órganos jurisdiccionales", https://www.fiscal.es/fiscal/PA_WebApp_SGNTJ_NFIS/descarga/ponencia $\% 20$ escrita $\% 20 \mathrm{Sra} \% 20$ Gamo.pdf $?$ idFile $=4 \mathrm{a} 5 \mathrm{a} 63 \mathrm{fc}-\mathrm{dfe} 5-47 \mathrm{ad}-$ 9802-90936202c254, pp. 1-26, pp. 8-9 y 14 [último acceso 04/06/2019], alude al deber general de las todas las entidades, tanto públicas como privadas, de colaborar con los Jueces y Tribunales previsto en el art. 17.1 LOPJ, señalando, además, que esta es la forma de colaboración preferente de la Administración Tributaria con los Tribunales, entre otras 
haría nacer, por lo tanto, en las partes personadas la posibilidad de impugnar su informe, así como de designar un perito de parte que contradiga el informe del funcionario designado judicialmente. Esta oportunidad de contradicción, de la que indudablemente debe de gozar el encausado, es un requisito absolutamente necesario para garantizar el derecho de defensa y la igualdad de armas, en tanto que principio basilar de cualquier proceso judicial.

Por otra parte, cuando quien es llamado como perito ha tenido un conocimiento previo y extraprocesal de los hechos, como ocurre señaladamente con los inspectores actuarios que, en el desarrollo de sus actuaciones administrativas de comprobación o inspección, detectan la comisión de un ilícito penal, puede haber problemas para determinar si tal sujeto debe de ser llamado en calidad de testigo, de perito o de testigo-perito ${ }^{49}$.

El testigo-perito es la persona que, poseyendo conocimientos especializados -científicos, técnicos o artísticos-, percibe un hecho extraprocesalmente, a base precisamente de aquellos, y es llamado al proceso para que refiera cuanto sepa sobre el mismo ${ }^{50}$. La figura no se prevé en la LECrim, pero sí en la LECiv, de aplicación supletoria a aquella, concretamente en su art. 370.4. A pesar de tal imprevisión en la legislación

cosas, porque permite aportar información que le consta a la Agencia Tributaria aun cuando no figure en el sumario.

49 Según las opiniones contenidas en AA.VV.: Alonso Alaya, M; Picazo González, P.; Malón Muñoz, A. (coords.) Memento experto. Perito judicial, cit., p. 66, párrafo 367, los inspectores de Hacienda deberían ser llamados como testigos cuando, tratándose del inspector actuante en sede administrativa, declarase exclusivamente sobre el expediente en el que participó, en calidad de testigo-perito si, adicionalmente, expresase sus criterios y opiniones técnicas en relación con lo actuado y como perito para el caso de que, sin haber intervenido previamente en sede administrativa, fuese llamado para manifestar sus conocimientos y criterios técnicos sobre el objeto del debate.

50 GÓMEZ ORBANEJA, E.; HERCE QUEMADA, V.: Derecho procesal penal, $10^{a}$ ed., Artes Gráficas y Ediciones, Madrid, 1986, p. 32 
procesal penal, es perfectamente posible que un sujeto en el que concurran tales características sea llamado a declarar en dicha calidad en el proceso penal ${ }^{51}$. De hecho, en el ámbito de la criminalidad económica y financiera, es habitual que el hecho delictivo sea descubierto o percibido por funcionarios públicos en el ejercicio de sus competencias inspectoras de naturaleza administrativa, los cuales, posteriormente son llamados al proceso judicial para aportar su conocimiento sobre el hecho delictivo descubierto y, al mismo tiempo, para apreciar, con sus específicos conocimientos, aquellas circunstancias fácticas consideradas técnicamente complejas ${ }^{52}$.

51 Así lo reconocen, entre otras, las siguientes resoluciones: STS (Sala 2a, Sección 1 ${ }^{\mathrm{a}}$ ) 1097/2011, de 25 de octubre (RJ 2012, 1254); STS (Sala 2a , Sección $1^{\mathrm{a}}$ ) núm. 163/2019, de 26 marzo (RJ 2019\1115) F. J. 5; STS (Sala $2^{\text {a }}$, Sección $1^{\text {a }}$ ) núm. 65/2019, de 7 febrero (RJ 20191522). Esta última, en su F. J. $2^{\circ}$, señala, refiriéndose a la prueba pericial de inteligencia, que la misma "ha sido configurada como pericial y testifical en razón a la duplicidad de quien así declara en juicio oral, ya que el agente policial que elabora el informe conoce del contenido de la materia y en consecuencia lo hace por sus conocimientos científicos, pero también actúa como testigo en razón de lo que sabe". Y, a continuación, establece una analogía con el testigo-perito regulado en la LECiv, señalando que: "Podría llegar a decirse que en estos casos la pericial de inteligencia se puede asemejar a la prueba del testigo-perito que fue incluida en la LEC en los artículos 370 y 380 por razón de la existencia de personas que podrían actuar en juicio de las dos maneras. En este sentido, la aplicación analógica nos permite llegar, frente a los detractores de considerar la pericial de inteligencia como una prueba mixta testifical/pericial, resolviendo el debate de las dudas que suscita su incardinación dentro del medio probatorio de la pericia en el proceso penal. De esta manera se le puede ubicar dentro de la prueba testifical sin olvidar la esencia de pericia de la que tampoco se puede olvidar su naturaleza en cuanto a que lo que el "testigo" declara lo es porque "lo sabe", y esto lo es por su preparación y conocimiento de este tipo de hechos, por lo que es preferible otorgarle un carácter mixto en orden a ubicarla dentro de los medios de prueba en el proceso penal".

52 SÁNCHEZ ULLED, E. J.: "Estrategias de investigación en los delitos económicos complejos. La criminalidad económica organizada" en M. A. Gimeno Jubero (Dir.) Estudios de Derecho Judicial, núm. 72, ejemplar dedicado a Derecho Penal económico, CGPJ, Madrid, 2006, pp. $11-48$, p. 33. 
Piénsese que, mientras el testigo declara sobre hechos percibidos por él de forma previa y ajena al proceso penal, el perito es llamado a declarar sobre hechos que obran en el sumario, para cuyo conocimiento o apreciación son necesarios sus conocimientos especializados ${ }^{53}$. De ahí que, haya quien opine que la llamada al proceso como testigo-perito del inspector actuario supone desvirtuar su llamamiento, ya que se le cita como perito, pero se le hace declarar como testigo, al pedirle que se pronuncie sobre hechos o experiencias que ha conocido al margen del proceso ${ }^{54}$.

Otros profesionales que, quizás, podrían encajar en la referida figura del testigo-perito serían aquellos integrantes de la entidad encausada que, poseyendo conocimientos técnicos o científicos sobre una concreta rama de la actividad de la empresa, hubiesen tenido un conocimiento directo sobre algunos de los hechos relevantes para el juicio penal. En particular, podría asumir tal condición el auditor contable de la entidad encausada, su abogado interno, en la medida en que no se encontrase protegido por el derecho al secreto y, especialmente, el compliance officer o encargado del programa de cumplimiento ${ }^{55}$.

Concretamente, el compliance officer, teniendo conocimientos específicos sobre los aspectos técnicos de la prevención delictiva, podría aportar su conocimiento personal y directo sobre los hechos acaecidos en el seno de la entidad investigada $\mathrm{o}$, incluso, el adquirido en su calidad de gestor del sistema interno de denuncias o de director de las investigaciones internas desarrolladas por la organización de for-

53 En este sentido, resulta ilustrativa la definición del perito que realiza GUASP DELGADO, J.: Derecho Procesal Civil, Instituto de Estudios Políticos, Madrid, 1962, p. 394, ya que pone el acento, entre otros aspectos, en el hecho de que su actividad recae sobre datos que habían adquirido ya índole procesal en el momento de su captación por el experto.

54 GAMO YAGÜE, R.: "Colaboración de la Agencia Estatal", cit., p. 11.

55 NEIRA PENA, A. M ${ }^{\mathrm{a}}$.: La defensa penal de la persona jurídica...cit., p. 239. 
ma previa al proceso judicial. Así pues, su actuación como testigo-perito, dada su cualificación profesional y su posible percepción directa de hechos relevantes para el juicio penal podría parecer adecuada, al menos cuando no hubiese sido designado por la persona jurídica para asumir su representación en el proceso, en tanto que, en tal caso, nada remoto ${ }^{56}$, el oficial de cumplimiento actuaría en una calidad más asimilada a la de acusado que a la de testigo. Y un razonamiento similar podría aplicarse, así mismo, al auditor de compliance o la entidad externa que se hubiere encargado, en su caso, de la certificación del programa de cumplimiento de la entidad encausada.

El problema básico que, a mi juicio, plantea el llamamiento de los referidos profesionales en calidad de testigo-perito tiene que ver con la imparcialidad que se le exige al perito, y de la que, probablemente, tales sujetos, carezcan, al menos si se entiende esta garantía como apariencia de objetividad. Piénsese que una de las causas de recusación de los peritos consiste, precisamente, en tener interés en el proceso (art. 468.2 ${ }^{\circ}$ LECrim), lo que podría sospecharse fundadamente de quien extraprocesalmente hubiese intervenido en la certificación, ya de la gestión, ya de las cuentas anuales, ya del programa de cumplimiento, que en el juicio se ponen en entredicho. A esto hay que añadir que la figura del testigo-perito, tal y como se avanzó, no se encuentra regulada en la LECrim, con lo que no está claro qué régimen de recusaciones y/o tachas se le aplicarían en caso de ser admitida en el proceso penal ${ }^{57}$.

56 De hecho, la Propuesta de Código Procesal Penal del año 2013, redactada por la Comisión Institucional creada por Acuerdo de Consejo de Ministros de 2 de marzo de 2012, para la elaboración de propuesta de texto articulado de la LECrim y presentada al Ministerio de Justicia el 25 de febrero de 2013, señalaba al director del sistema de cumplimiento como representante de la entidad en el proceso (art. 51. 1 Propuesta CPP). El texto de la propuesta está disponible en: https://e00-elmundo. uecdn.es/documentos/2013/06/04/codigo_procesal_penal.pdf [último acceso: 20/10/2020]

57 Según la regulación contenida en la LECiv sobre el testigo-perito, "Cuando el testigo posea conocimientos científicos, técnicos, artísticos o 


\section{La garantía de imparcialidad del perito económico}

Los peritos, tanto los nombrados por el juez como los designados por las partes, han de ser imparciales. De ahí que la ley exija que todos ellos presten juramento "de proceder bien y fielmente en sus operaciones y de no proponerse otro fin más que el de descubrir y declarar la verdad" (art. 474 LECrim). Además, para garantizar su imparcialidad se prevén mecanismos de abstención y de recusación.

Las causas legales de recusación de los peritos son las siguientes: el parentesco por consanguinidad o afinidad dentro del cuarto grado con el querellante o el reo; el interés directo o indirecto en la causa o en otra semejante y la amistad íntima o enemistad manifiesta (art. 468 LECrim).

Las causas de recusación relativas al parentesco, evidentemente, son sólo aplicables a relaciones entre personas físicas y se trata de causas cuya concurrencia resulta objetivamente verificable. En cuanto a la amistad o enemistad, el Tribunal Constitucional ha señalado, así mismo, que también son cualidades predicables únicamente de las personas físicas, con lo que no se puede ser amigo o enemigo de una entidad u organización ${ }^{58}$. Sobre esta causa, parece quizás

prácticos sobre la materia a que se refieran los hechos del interrogatorio, el tribunal admitirá las manifestaciones que en virtud de dichos conocimientos agregue el testigo a sus respuestas sobre los hechos. En cuanto a dichas manifestaciones, las partes podrán hacer notar al tribunal la concurrencia de cualquiera de las circunstancias de tacha relacionadas en el artículo 343 de esta Ley" (art. 370.4); Sin embargo, en el proceso penal, tanto los peritos judiciales como los de parte pueden ser objeto de recusación (arts. 469, 470, 662, 723 y 724 LECrim), mientras que, al no preverse las tachas, la relación de los testigos con las partes o su interés en el objeto del proceso será puesta de manifiesto por el declarante al contestar a las preguntas generales de la ley (art. 436 y 708 LECrim), pudiendo, en su caso, ser tomadas en consideración por el juez a la hora de valorar libremente la prueba.

58 Según el Tribunal Constitucional, "tanto la amistad como la enemistad pertenecen a la esfera subjetiva de los sentimientos y sólo pueden predicarse de las personas físicas. Quedan, por lo tanto, excluidos como 
oportuno señalar que el hecho de haber trabajado el perito previamente con el letrado en otros asuntos o causas o, incluso, el hecho de que entre el abogado y el perito exista una relación de colaboración profesional más o menos estable no debe considerarse, en principio, suficiente para entender que hay una amistad íntima.

Sin embargo, la causa consistente en tener interés directo o indirecto en la causa o en otra semejante resulta de más difícil determinación y es mucho más amplia en cuanto a su ámbito de aplicación, hasta el punto de que se hace necesario interpretarla de modo restrictivo para que no pierda su razón de ser, impidiendo que un perito pueda dar su opinión experta en varias causas independientes entre sí, simplemente porque, en ellas, la duda técnica planteada sea semejante ${ }^{59}$.

Especialmente conflictivos, en el marco de las periciales económicas, ya contables o de compliance, ya de otro tipo, resultan aquellos supuestos en los que entre el perito y la parte existen otras relaciones comerciales, de asesoramiento o de otra naturaleza, y el mantenimiento de tales relaciones puede hacer sospechar de las motivaciones del perito, que podría tener incentivos para actuar de forma parcial. Así, por ejemplo, los despachos multiservicio, que ofrecen múltiples productos, que pueden ir de la evaluación de riesgos, a la consultoría y la auditoría, pasando por el asesoramiento financiero

indicador verosímil de amistad o enemistad los meros sentimientos de inclinación o de rechazo deducidos del hecho de la pertenencia a partidos políticos, asociaciones, corporaciones o grupos sociales, así como en relación a la asunción de creencias religiosas e ideologías de signo diverso, mientras no se hayan traducido en actos individualizados de amistad o enemistad" (ATC de 17 de septiembre de 2013, F.J. $5^{\circ}$ ).

59 Según SAIZ DÍAZ, C.: "La prueba pericial de contenido económico...", cit., p. 26 , la referencia al interés en otra causa semejante debe de entenderse como aquella en que exista una vinculación entre las personas o empresas implicadas, o que ambas causas deriven de la misma operación o negocio jurídico. Por lo tanto, como base para la recusación, no basta con que las causas sean objetivamente similares, en cuanto a su temática o en cuanto a la duda técnica planteada. 
y/o fiscal, podrían encontrarse en una situación en la que el interés en mantener una determinada relación comercial con alguno de sus clientes pusiese en duda la imparcialidad de sus empleados para actuar como peritos en el proceso $^{60}$.

Al referido riesgo de potenciales conflictos de interés, hay que añadir el hecho de que la designación de peritos en los procesos por delitos contra el patrimonio o el orden socioeconómico viene recayendo, mayoritariamente, en profesionales que desarrollan su función en el ámbito privado, lo que genera ciertos riesgos específicos en cuanto a la objetividad e imparcialidad de su actuación. En este sentido, hay que tomar en consideración que sólo cuando, por razón de la materia a que se refiera el informe, no existan técnicos u organismos dependientes de la Administración de Justicia o funcionarios, organismos o servicios técnicos dependientes de otras Administraciones públicas, se recurrirá a la designación de peritos privados ${ }^{61}$. De ahí que, en los delitos contra

60 Se puede encontrar un ejemplo reciente de esta problemática en el caso Bankia y, concretamente, en la situación de la entidad Deloitte. Primero, por el tipo de actividad que realiza esta última, que podría hacerla idónea para asumir el encargo pericial, ya como perito contable, ya como perito de compliance. Segundo, debido a su oferta multiservicio, que abarca la evaluación de riesgos, la consultoría, la auditoría contable y el asesoramiento financiero. Tercero, por su tamaño, que hace más probable que pueda actuar en distintas causas entre las que pueda haber vínculos, dada la cuota de mercado que ocupa en auditoría y consultoría. Cuarto, por los motivos por los que la Audiencia Nacional ha decido imputarla en el caso BANKIA. Así, el AAN (Sala de lo Penal), de 15 de septiembre de 2017, señala que "resulta difícil afirmar sin cuestionamiento que la sociedad fiscalizó adecuadamente las sucesivas auditorías siendo que al tiempo se producía un beneficio para la entidad; es por ello que debe continuar vigente la acción penal y deslindar en otro momento procesal, si se han adoptado todas las políticas de prevención de riesgos penales para la exención de responsabilidad criminal”. Y, añade, la referida resolución judicial, que el beneficio para Deloitte "pudiera haber radicado en el mantenimiento a todo trance de la relación contractual entre la auditadas y Deloitte SL".

61 VEGAS TORRES, J.: "Análisis sobre la prueba pericial en la Ley de Enjuiciamiento Civil y en el proceso penal español”, en LAGUNA 
la Hacienda Pública se recurra usualmente a los funcionarios de la Agencia Tributaria, recurso no disponible cuando se trata de realizar informes periciales contables, de auditoría de cuentas o de compliance, entre otros.

Con la generalización de los programas de cumplimiento normativo en las empresas, ha surgido la auditoría de compliance, esto es, la actividad profesional encaminada a evaluar si un determinado modelo de cumplimiento está correctamente diseñado e implementado y si, por lo tanto, resulta eficaz para prevenir delitos en el seno de una organización ${ }^{62}$. Pues bien, con la actividad de auditoría o certificación de la eficacia de los programas de cumplimiento nace la figura del auditor o certificador de compliance. En relación con esta figura, la regulación española no señala nada, con lo que se abre la posibilidad de que cualquier empresa de asesoría, consultoría o auditoría pueda emitir certificaciones sobre los modelos de compliance penal ${ }^{63}$.

SÁNCHEZ, P., et al. La prueba pericial económica en el ámbito procesal español, Universidad Rey Juan Carlos, Madrid, pp. 51-71, p. 67, disponible en https://burjcdigital.urjc.es/bitstream/handle/10115/12106/ Prueba_Pericial_Economica.pdf?sequence $=1$ \&isAllowed=y [último acceso: 20/10/2020]

62 Según NIETO MARTÍN, A.: "Fundamento y estructura de los programas de cumplimiento normativo", en Nieto Martín, A. (Dir.) Manual de cumplimiento penal en la empresa, Tirant lo Blanch, Barcelona, 2015, pp. 111-134, p. 116, las certificaciones de programas de cumplimiento podrían ser consideradas como una prueba pericial anticipada.

63 Por su parte, la regulación chilena, que prevé específicamente la posibilidad de que los programas de prevención delictiva sean certificados por una entidad externa, especifica que la función de certificación puede ser desempeñada por empresas de auditoría externa, por sociedades clasificadoras de riesgo o por otras entidades registradas ante la Comisión para el Mercado Financiero, concretamente, en el Registro de Entidades Certificadoras de Modelos de Prevención de Delitos. Actualmente, en Chile, existen más de una treintena de entidades habilitadas como certificadoras de los modelos de prevención de delitos, estando el listado disponible en http://www.cmfchile.cl/portal/principal/605/w3-propertyvalue-18578.html [último acceso: 20/10/2020] 
El hecho de que sean empresas privadas las que se encarguen de certificar la eficacia de los programas de prevención de delitos, sin que además exista un procedimiento de certificación reglado, presenta el riesgo de que surjan situaciones de conflicto de interés entre las entidades certificadoras y las empresas que pretenden que sus programas sean certificados. Por eso, resulta muy adecuada, aunque quizás excesivamente limitada en cuanto a su ámbito de aplicación, la incompatibilidad señalada en la norma chilena, dictada por la Superintendencia de Valores y Seguros (actual Comisión para el Mercado Financiero) de aquel país, según la cual se prohíbe a las sociedades certificadoras emitir certificados en favor de entidades a las que previamente han asesorado en relación con el diseño e implementación del modelo de prevención, así como en favor de otras relacionadas con aquellas o pertenecientes al mismo grupo o integradas en un grupo empresarial con la propia entidad certificadora ${ }^{64}$.

En mi opinión, la incompatibilidad para certificar la eficacia del modelo de cumplimiento debería resultar igualmente extensible a otras relaciones comerciales que la certificadora pudiera establecer con la entidad certificada, por ejemplo, en calidad de asesora legal, consultora o auditora contable, entre otras. Y ello, porque la independencia y la neutralidad del certificador son clave para determinar la

64 Sección III, norma de carácter general 302, de 25 de enero de 2011, emitida por la Superintendencia de Valores y Seguros (actualmente, Comisión para el Mercado Financiero) que establece normas que deben cumplir las empresas de auditoría externa, sociedades clasificadoras de riesgo y demás entidades para desempeñar la labor de certificación de modelos de prevención de delitos a que se refiere la Ley 20.393, disponible en: http://www.cmfchile.cl/normativa/ncg_302_2011.pdf [último acceso: 20/10/2020]. Esta norma establece, además de las señaladas incompatibilidades en cuanto a los servicios que pueden prestar las entidades certificadoras, la obligación, para estas entidades, de inscribirse en un Registro público ad hoc, los requisitos de la inscripción, el contenido mínimo del certificado, algunas cuestiones relativas a su regulación interna de las mismas y sus obligaciones profesionales básicas. 
calidad y la fiabilidad de estos servicios ${ }^{65}$. Acudiendo a la terminología propia de la auditoría contable, al auditor de compliance debería exigírsele actuar con el necesario "escepticismo profesional", entendido como una actitud que incluye una mentalidad inquisitiva, una especial atención a las circunstancias que puedan ser indicativas de posibles incorrecciones debidas a errores o fraudes y una valoración crítica de la evidencia de auditoría ${ }^{66}$.

Continuando con la misma lógica, pero ahora aplicada al ámbito procesal, si quien es llamado a actuar como perito de compliance pertenece a la entidad que se encargó de certificar o auditar el programa de cumplimiento de forma previa al proceso, tal persona sería, seguramente, recusable, por tener interés en la causa. Por lo tanto, parece que, en tal supuesto, lo más correcto será llamar al auditor del programa de compliance como testigo, para que comparta con el Tribunal su conocimiento extraprocesal de los hechos ${ }^{67}$. Y ello es así porque, como perito, tal profesional podría ser objeto de recusación, al menos cuando la pericia presentada en instrucción no pudiera repetirse en la fase de juicio oral (art. 467 LECrim) o cuando se pretendiese hacerla valer como prueba en el plenario (arts. 723 y 662 LECrim). Otra opción podría consistir en citarle en calidad de testigo-perito, apli-

65 En este sentido, NIETO MARTÍN, A.: "Fundamento y estructura de los programas...", p. 117, afirma que un aspecto central en la regulación de la certificación es asegurar la independencia y profesionalidad de las entidades certificadoras.

66 Definido en la Norma Internacional de Auditoría 200.13 (1) (adaptada para su aplicación en España mediante Resolución del Instituto de Contabilidad y Auditoría de Cuentas, de 15 de octubre de 2013) disponible en: http://www.icac.meh.es/nias/nia $\% 20200 \% 20$ p $\% 20$ def.pdf [último acceso: $20 / 10 / 2020]$

67 En esta línea, se encuadra la propuesta de SAIZ DÍAZ, C.: "La prueba pericial de contenido económico...", cit., p. 27, en relación con los Inspectores de Hacienda que han sido actuarios en el previo expediente administrativo de comprobación, los cuales, en opinión del autor, deberían de ser llamados como testigos y no como peritos. 
cándosele la regulación de la LECiv respecto de esta figura ${ }^{68}$, según la cual, respecto de los conocimientos técnicos que el testigo-perito agregue a su declaración, las partes podrán hacer notar al tribunal la concurrencia de circunstancias de tacha (art. 370.4 LECiv), las cuales serán tomadas en consideración por el juzgador a la hora de valorar su declaración (art. 376 LECiv).

En definitiva, igual que resulta inaceptable que quien lleva la contabilidad en una empresa se encargue de auditar sus cuentas, tampoco se justifica que quien se haya encargado de la auditoría de las cuentas de una entidad sea posteriormente llamado al proceso para emitir un informe pericial acerca de la fiabilidad de tales apuntes contables, en tanto que parece claro que tal sujeto tendrá un interés, cuando menos profesional, en avalar el trabajo que ha realizado extraprocesalmente.

Pues bien, el mismo razonamiento es extensible a la labor de certificación y pericia de compliance. Así pues, mutatis mutandis, quien diseñó el modelo de cumplimiento o quién se encargó de su implementación o de su supervisión, no debiera ser quien emita un certificado sobre su eficacia preventiva. Y, del mismo modo, la entidad certificadora no deberá actuar como perito en el marco de un proceso judicial, en tanto que su imparcialidad estará en entredicho, dado su evidente interés objetivo en contribuir a la acreditación de la adecuación y eficacia del programa por ella certificado ${ }^{69}$.

68 Hay que recordar, en este punto, que la LECrim no regula la figura del testigo-perito que, sin embargo, es admitida por los Tribunales del orden jurisdiccional penal. Véase, en este sentido, la STS (Sala $2^{\mathrm{a}}$ ) de 17 de febrero de 1981 (RJ 1981\660), donde se señalaba que "no debe de rechazarse el testimonio de una persona que puede aportar hechos y sus circunstancias a través de sus percepciones sectoriales a la vez que juicios de valor autorizados por sus conocimientos especiales en una ciencia, arte o práctica, observadas como han sido las formalidades procesales para cada prueba en particular".

69 NEIRA PENA, A. M ${ }^{\text {a }}$.: La defensa penal de la persona jurídica... cit., p. 302. 
Otra cuestión que cabría plantearse, que está en cierta medida vinculada con la eventual participación del auditor de cuentas o del certificador del programa de cumplimiento en el proceso, tiene que ver con la eficacia probatoria del informe de auditoría o de la certificación de cumplimiento. Parece evidente que tales elementos de prueba se introducirán en el proceso como prueba documental, y nunca como informes periciales, debiendo el auditor o certificador, en su caso, ser llamado como testigo, por las razones ya referidas ${ }^{70}$.

Además, para valorar adecuadamente los referidos documentos hay que tener en cuenta que tanto su perspectiva y alcance como su metodología pueden ser distintos de los empleados en un informe pericial. En este sentido, hay que tomar en consideración que un informe de auditoría y una opinión de auditoría solicitada en el marco de una pericia podrían llegar legítimamente a conclusiones diferentes, dado que, lo que es relevante para la pericial puede no serlo para la auditoría por aplicación del principio de materialidad ${ }^{71}$.

Algo similar a lo que ocurre entre el informe de auditoría y la pericial contable, puede afirmarse en relación con las certificaciones y periciales de compliance. Así pues, mientras que las primeras tienen una perspectiva ex ante, que atiende a la idoneidad del modelo en abstracto para prevenir los riesgos determinados por la evaluación de riesgos, la pericial de compliance incluye también un análisis ex post $7^{72}$,

70 MAGRO SERVET, V.: "Viabilidad de la pericial de compliance para validar la suficiencia del programa de cumplimiento normativo por las personas jurídicas", Diario La Ley, núm. 9337, 2019, pp. 1-7, p. 7, se refiere al valor del certificado de validación de compliance conforme a la norma UNE 19601 como prueba documental.

71 AA.VV.: Alonso Alaya, M; Picazo González, P.; Malón Muñoz, A. (coords.) Memento experto. Perito judicial, cit., p. 148, párrafo 1110.

72 En este sentido, tal y como afirma GOÑI SEIN, J. L.: "Programas de cumplimiento empresarial...", pp. 374-375, el plan de prevención se diseña -y se audita o certifica- desde una perspectiva ex ante, mientras que, evidentemente, la responsabilidad se determinará desde una perspectiva ex post. 
que se realiza tras la comisión del hecho presuntamente delictivo, y que trata de determinar en qué medida, en el caso concreto, los instrumentos de control de la entidad funcionaron adecuadamente, ya a la hora de prevenir, ya a la hora de detectar, el ilícito en cuestión, en qué medida la evaluación de riesgos valoró adecuadamente la posibilidad de comisión de delitos de la naturaleza del presuntamente perpetrado y en qué medida la organización implementó controles adecuados para prevenir dicho riesgo en concreto $^{73}$. De ahí que un programa certificado pueda ser considerado inidóneo tras constatarse que se ha cometido un delito y que, en relación con el concreto riesgo materializado, se ejercieron de forma insuficiente o inadecuada los deberes de control. Es por eso que las certificaciones, por sí solas, no garantizan la eficacia del programa de cumplimiento ni, por supuesto, la exención de responsabilidad del ente ${ }^{74}$.

73 Sobre el análisis concreto del delito supuestamente cometido como objeto del peritaje, se indica que deberán individualizarse los elementos básicos del delito cometido en relación con los sujetos que lo cometieron, así como los controles a los que se encontraban sometidos, detallándose los siguientes aspectos: años en la empresa y departamentos en los que ha trabajado el sujeto; existencia de red flags o antecedentes de comportamiento similar del sujeto en el pasado; probabilidad de que el sujeto cometiese el delito; órgano o departamento supervisor del sujeto y posibles fallos en su supervisión; motivación del sujeto en cometer el delito; modus operandi; medidas que debían ser aplicadas directamente sobre el sujeto según el plan de compliance; medidas de prevención que el sujeto eludió fraudulentamente; investigación realizada por la empresa al detectar el delito; pruebas aportadas por la empresa y medidas tomadas por la empresas para detener la continuidad delictiva (AA.VV.: Alonso Alaya, M; Picazo González, P.; Malón Muñoz, A. (coords.) Memento experto. Perito judicial, cit., pp. 356-357, párrafos 3222-3228).

74 Según la Fiscalía General del Estado "Las certificaciones sobre la idoneidad del modelo expedidas por empresas, corporaciones o asociaciones evaluadoras y certificadoras de cumplimiento de obligaciones, mediante las que se manifiesta que un modelo cumple las condiciones y requisitos legales, podrán apreciarse como un elemento adicional más de su observancia pero en modo alguno acreditan la eficacia del programa, ni sustituyen la valoración que de manera exclusiva compete al órgano judicial" (FGE, Circular 1/2016, p. 52) 
Por último, quisiera hacer referencia en este epígrafe a la particular posición de los Inspectores de la Agencia Tributaria en delitos contra la Hacienda Pública. Tanto en los casos en que previamente han actuado en el procedimiento administrativo como en los supuestos en que son nombrados posteriormente, tras el correspondiente llamamiento judicial, la imparcialidad objetiva de tales funcionarios constituye una cuestión históricamente controvertida. En este sentido, se arguye que los funcionarios de la Agencia Tributaria podrían tener un interés directo cuando hubiesen sido los inspectores actuarios en el procedimiento administrativo previo y, en todo caso, un interés indirecto por su condición de funcionarios de la administración personada en el proceso, normalmente como acusación particular, en las causas por delito fiscal, actuando a través de la abogacía del Estado ${ }^{75}$.

Sin embargo, la doctrina del Tribunal Supremo, consolidada ya desde hace décadas, ha venido a negar que se pueda recusar a los funcionarios de la Agencia Tributaria por falta de imparcialidad objetiva ${ }^{76}$. Se argumenta, en este

75 SAIZ DÍAZ, C.: "La prueba pericial de contenido económico...”, cit., p. 26.

76 Véanse, entre otras, las siguientes resoluciones al respecto: STS (Sala 2 $2^{\mathrm{a}}$ ) núm. 192/2006, de 1 febrero (RJ 2006\1042); STS (Sala 2a ${ }^{\mathrm{a}}$, Sección $1^{\mathrm{a}}$ ) núm. 611/2009, de 29 mayo (RJ 2009\4202). En esta última sentencia, y con cita de otras anteriores, indica el Tribunal Supremo lo siguiente: "Tiene declarado esta Sala, respecto al valor que tienen los dictámenes periciales emitidos por los Inspectores de la Agencia Tributaria (...) que dichos informes, en causas en las que la referida Agencia inicia mediante denuncia el procedimiento penal, que la vinculación laboral de estos Inspectores, que tienen la condición de funcionarios públicos, con el Estado, titular del ius puniendi, no genera ni interés personal que les inhabilite, por lo que ni constituye causa de recusación ni determina pérdidas de imparcialidad". Por su parte, la STS (Sala 2a) núm. 2069/2002, de 5 diciembre (RJ 2003।5) señala que "la admisión como Perito de un Inspector de Finanzas del Estado en un delito Fiscal, no vulnera los derechos fundamentales del acusado, atendiendo, precisamente a que el funcionario público debe servir con objetividad a los intereses generales, sin perjuicio, obviamente, del derecho a la parte a proponer una prueba pericial alternativa a la ofrecida por el Ministerio Fiscal". 
sentido, que las causas de recusación deben de interpretarse restrictivamente cuando se trata de funcionarios públicos, pertenecientes a instituciones especializadas en el objeto de la pericia, los cuales, muchas veces, se muestran como los peritos más cualificados dada su especialización, siendo que, además, tales profesionales actúan el interés público al que sirven (art. $103 \mathrm{CE})^{77}$.

Por lo tanto, según jurisprudencia reiterada del Tribunal Supremo, la imparcialidad de los miembros de la Agencia Tributaria se deriva, precisamente, de su condición de funcionarios, sin perjuicio del derecho de la parte a discrepar de su dictamen y, en su caso, de encargar una pericial alternativa y contradictoria. Y, así mismo, se sostiene que la vinculación laboral con la Administración personada no genera un interés personal. En este sentido, JimÉnEZ VILlAREJo sostiene que el interés causante de recusación debe de ser el interés meramente personal, en ningún caso el que se deriva del cumplimiento de los deberes propios del cargo ${ }^{78}$. De ahí que, según el referido autor, no resulta admisible pretender que la intervención de los funcionarios públicos en un determinado expediente administrativo los descalifica para actuar objetivamente cuando dicho expediente se incorpora a un proceso penal ${ }^{79}$.

Ahora bien, la presunción de imparcialidad por parte de los funcionarios de la Agencia Tributaria, derivada de forma automática de su condición funcionarial, no es una cuestión unánime. Según Marchena Gómez, "cuando la aportación del ayudante técnico jurídico (o del perito, según

77 JIMÉNEZ VILLAREJO, C.: "La prueba pericial en los delitos económicos (con particular referencia a la intervención de los Inspectores de Finanzas del Estado)", Jueces para la democracia, núm. 31, 1998, pp. 59-67, p. 64.

78 JIMENEZ VILLAREJO, C.: "La prueba pericial en los delitos...", cit., p. 64.

79 JIMENEZ VILLAREJO, C., "La prueba pericial en los delitos...”, cit., p. 64 . 
se produzca su llamada al procedimiento) viene suministrada por la propia Administración perjudicada, la silueta del instituto de la recusación se desdibuja con trazo grueso" "80. Sobre todo, si se tiene en cuenta la libertad que la Administración tiene para designar libremente como perito a cualquiera de sus funcionarios, así como para sustituirle o relevarle de sus funciones ${ }^{81}$.

Por último, cabe señalar que la posibilidad de recusar a los peritos judiciales en la fase de instrucción se encuentra limitada por ley a aquellos casos en que la pericial no pudiera reproducirse en el juicio oral (art. 467 LECrim). Esta circunstancia no se dará, normalmente, con las periciales económicas, que podrán ser repetidas, ratificadas y sometidas a la debida inmediación y contradicción, a través de la declaración del perito en el plenario ${ }^{82}$, por lo que su recusación se debería plantear en la fase intermedia, tras ser la pericial propuesta y admitida como prueba a practicar en el plenario (arts. 723 y 662 LECrim).

80 MARCHENA GÓMEZ, M.: "De peritos, cuasiperitos y pseudoperitos", cit., p. 246.

81 Véase, sobre este particular, la Instrucción $2 / 2013$, de 4 de octubre, de la Dirección General de la Agencia Estatal de Administración Tributaria sobre designación de funcionarios como peritos o en otras funciones de auxilio judicial, disponible en: https://www.google.com/url?sa=t\&rc $\mathrm{t}=\mathrm{j} \& \mathrm{q}=\&$ esrc $=\mathrm{s} \&$ source $=$ web\&cd $=1 \& \mathrm{ved}=2 \mathrm{ahUKEwi} 2 \mathrm{nLXNopnjA}$ hXC8OAKHWybCz0QFjAAegQIARAC\&url=http $\% 3 \mathrm{~A} \% 2 \mathrm{~F} \% 2 \mathrm{Fest}$ aticos.elmundo.es $\% 2$ Fdocumentos $\% 2 \mathrm{~F} 2013 \% 2 \mathrm{~F} 11 \% 2 \mathrm{~F} 27 \% 2 \mathrm{Finstruc}$ cion.pdf\&usg=AOvVaw2Kovzxw2vBY7O7c1D0ugvc [último acceso: 20/10/2020]

82 Según el Tribunal Constitucional, el art. 467 LECrim encontraría su razón de ser en el hecho de que la parcialidad de los peritos sólo presenta relevancia constitucional cuando la pericia asume valor de prueba preconstituida, y no cuando pueda reproducirse en el juicio oral, ya que, en este último caso, garantizadas la inmediación y la contradicción, el órgano judicial podrá valorar todas las circunstancias del desarrollo de la pericia sopesando, en su caso, la influencia que en el desarrollo de la misma pudiera tener un eventual interés del perito con el hecho o con las partes (ATC 126/2004, 19 de abril de 2004 (F. J. $2^{\circ}$ )). 


\section{El momento procesal adecuado para aportar los dictáme- nes periciales}

Los peritos judiciales pueden ser designados en cualquier momento durante la fase de instrucción, sin que existan plazos preclusivos que limiten esta posibilidad. Tal y como indica Vegas Torres, "el momento en que se ordene la realización de un informe dependerá de cuándo se ponga de manifiesto la necesidad de intervención de peritos", lo cual, en definitiva, vendrá casuísticamente determinado por los avances de la investigación ${ }^{83}$.

Sin embargo, de la lectura conjunta de los arts. 467 y 471 LECrim parece deducirse que la posibilidad de que las partes nombren peritos a su costa en la fase de instrucción, al igual que ocurre, tal y como se indicó ut supra, con la posibilidad de recusar a los peritos judiciales, se encuentra limitada a aquellos supuestos en los que el reconocimiento e informe periciales no puedan reproducirse en el juicio oral. Esta limitación encontraría su sentido en el hecho de que, solo tratándose de pericias irreproducibles, su práctica con todas las garantías, incluida la posibilidad de contradicción, posibilitaría que adquiriesen valor probatorio, las practicadas en instrucción.

Pues bien, de ser aplicada de forma taxativa la anterior limitación, se debería concluir que las periciales económicas, como norma general, no podrían ser propuestas por las partes durante la instrucción. Y ello, debido a que este tipo de pericias, normalmente, son reproducibles en el juicio oral, dado que al basarse en el análisis de documentos y emitirse por escrito pueden ser revisadas cuantas veces resulte conveniente ${ }^{84}$.

83 VEGAS TORRES, J.: "Análisis sobre la prueba pericial...", cit., p. 67.

84 En este sentido, tal y como afirma BALAGUÉ DOMÉNECH, J. C.: La prueba pericial contable en los jurisdicciones civil, penal, contenciosoadministrativa y laboral, $5^{\text {a }}$ ed., Bosch, Madrid, 2007, p. 111, "el informe de la pericial contable, siendo emitido por escrito, y pudiendo ser 
Ahora bien, aunque la LECrim no lo regula, es práctica extendida, y ampliamente aceptada por los tribunales penales, la admisión de informes periciales de parte con la querella ${ }^{85}$, así como la aportación de los mismos durante la fase de instrucción, siendo el criterio de admisibilidad el previsto con carácter general para las diligencias de investigación de la fase de instrucción ${ }^{86}$. Por lo tanto, se admitirán los informes periciales de parte presentados con la querella, salvo que hacerlo resultase contrario a las leyes, innecesario o perjudicial para el proceso (art. 312 LECrim). Es más, según el Tribunal Constitucional, las diligencias de investigación, incluidos, por lo tanto, los dictámenes periciales tendentes a esclarecer los hechos, deben de aportarse durante la fase de instrucción, antes, por lo tanto, de que el juez instructor la clausure $^{87}$.

Esta posibilidad, consistente en aportar informes periciales de parte en la fase de instrucción, cobra especial importancia para la defensa cuando la pericia puede resultar determinante de la relevancia penal de la conducta. En este sentido, tal y como sostiene VeGas Torres los informes periciales, con frecuencia, son factores muy influyentes en la decisión judicial de sobreseimiento y archivo o de formulación de la acusación y apertura del juicio oral, por lo que, desde la perspectiva del imputado, hay que tener muy presente que

la prueba reconocida y revisada cuantas veces se estime conveniente, incluso por otros peritos", sería reproducible "por lo que los peritos contables no habrán de poder ser recusados por las partes querellante y querellada".

85 De hecho, tal y como afirma VEGAS TORRES, J.: "Análisis sobre la prueba pericial...", cit., p. 65, "En particular, es frecuente que las querellas por delitos de estafa, apropiación indebida, delito fiscal y delitos societarios, entre otros, se acompañen de informes periciales económicofinancieros que, partiendo de documentación bancaria y contable, precisan los movimientos de fondos sin justificar y demás irregularidades que se narren en la "relación circunstanciada del hecho" de la querella".

86 VEGAS TORRES, J.: "Análisis sobre la prueba pericial...", cit., p. 66.

87 STC 173/2000, de 26 de junio, F. J. $5^{\circ}$. 
contar en la instrucción con informes periciales favorables y convincentes puede facilitar una exoneración anticipada de responsabilidad evitando el juicio oral y la denominada "pena de banquillo"88. Piénsese, por ejemplo, en la importancia de acreditar la eficacia de los modelos de cumplimiento en fase de instrucción a la hora de determinar la responsabilidad penal de una persona jurídica o en la relevancia que una pericial contable podría tener para determinar la inexistencia de manipulaciones de la contabilidad en una causa por delito de falsificación de cuentas anuales.

En el caso de la pericial de compliance, se hace especial hincapié en el interés de la persona jurídica investigada en evitar el riesgo reputacional derivado de sentarse en el banquillo, para lo cual resulta absolutamente necesario que el dictamen pericial se aporte a la causa en la fase de instrucción. En este sentido, a pesar de que según el Tribunal Supremo, tal y como se indicó ut supra, la carga de probar la inexistencia o ineficacia de los compliance recae sobre la acusación $^{89}$, tal y como observa MAGRo SERVET, es posible que la entidad quiera "mover ficha", anticipándose a la acusación, a través de la designación de un perito en la instrucción, con el fin de acreditar la eficacia de su modelo de prevención delictiva, tratando así de evitar su acusación formal a través del archivo de las diligencias previas ${ }^{90}$. En este sentido, se afirma que, con independencia de a quien corresponda la carga de la prueba sobre la idoneidad y eficacia de los compliance, a la entidad le interesará acreditar su existencia, eficacia e idoneidad lo antes posible, dado que el daño reputacional, en gran parte derivado de la publicidad del plenario, es probablemen-

88 VEGAS TORRES, J.: "Análisis sobre la prueba pericial...", cit., p. 69.

89 STS (Sala 2a , Sección $1^{\mathrm{a}}$ ) núm. 154/2016, de 29 de febrero (RJ 20161600), F. J. $8^{\circ}$.

90 MAGRO SERVET, V.: "Hacia la creación del registro de expertos", cit., p. 4. 
te el mayor perjuicio que para la entidad se puede derivar del proceso penal ${ }^{91}$.

En este punto, resulta oportuno hacer una breve alusión a un fenómeno muy extendido en el imaginario colectivo estadounidense que se ha dado en llamar death by indictment o muerte por acusación. Según esta teoría, la presentación de cargos o la formalización de un proceso frente a un ente colectivo, especialmente cuando se trata de una sociedad cotizada, podría provocar daños irreparables para el posicionamiento de la misma en el mercado, aun cuando el proceso acabase con una absolución ${ }^{92}$. A este respecto, se hace hincapié en los perjuicios, tanto para el patrimonio como para la imagen de la entidad, que se derivarían de la mera imputación o procesamiento ${ }^{93}$, independientemente de cual fuese el resultado del proceso ${ }^{94}$.

91 AA.VV.: Alonso Alaya, M; Picazo González, P.; Malón Muñoz, A. (coords.) Memento experto. Perito judicial, cit., p. 352, párrafo 3182; En la misma línea, MAGRO SERVET, V.: "Hacia la creación del registro de expertos", cit., p. 5, hace hincapié en que "la presencia de la persona jurídica en el plenario en su condición de acusada le provoca un coste reputacional (Reputation Risks). Y este es uno de los mayores enemigos de la empresa".

92 Reproduzco aquí, por su claridad, las palabras literales de WRAY, C. A.; HUR, R. K.: "The power of the corporate charging decisions over corporate conduct", Yale Law Journal Pocket Part, núm. 116, 2007, pp. $306-311$, p. 306: "indictment alone, prior to any litigation, usually results in the death of any business entity by means of reputational damage in the marketplace and damage to the financial interests of its shareholders and investors".

93 Sobre el estigma derivado del procesamiento de las personas jurídicas, tanto desde el punto de vista económico como social, véase GIMENO BEVIÁ, J.: Compliance y proceso penal. El proceso penal de las personas jurídicas, Aranzadi, Navarra, 2016, pp. 176-177.

94 De hecho, uno de los argumentos que se emplean para defender la introducción del principio de oportunidad en las causas seguidas frente a las personas jurídicas, de tal forma que, a través de su colaboración con la Administración de Justicia, se les permita evitar la acusación formal en un proceso penal, se fundamenta en el afán por evitar o minimizar los daños colaterales que, supuestamente, podrían derivarse de la mera 
Ahora bien, tampoco se debe ocultar que, en ciertos supuestos, la complejidad del análisis que será preciso desarrollar para determinar si, efectivamente, el programa de cumplimiento era eficaz para la prevención del delito cometido y si cumplía con las exigencias legales que el CP impone, puede requerir sentar a la entidad en el banquillo y proceder a la práctica de las pruebas útiles y pertinentes a tal fin en el marco del plenario. En este sentido, ha de quedar claro que, en principio, sólo se procederá a sobreseer el proceso, cuando de la instrucción resulte evidente, sin necesidad de abrir el juicio oral, que la entidad contaba con medidas eficaces para prevenir el delito, ya que sólo en tal supuesto aparecerá la entidad indudablemente exenta de responsabilidad penal, tal y como exige el art. 640 LECrim para proceder a acordar el sobreseimiento libre por el motivo previsto en el art. $637.3^{\circ}$ LECrim.

En cualquier otro escenario, es decir, si existen dudas acerca de la concurrencia de cualquiera de los requerimientos legales exigidos para que la entidad quede exenta de responsabilidad, lo procedente será formular una acusación formal, abrir el juicio oral y practicar, ante una autoridad judicial independiente e imparcial, las pruebas útiles y pertinentes que permitan acreditar tales extremos. Rige, por lo tanto, en esta primera fase del proceso penal, una suerte de principio in dubio contra reo, de tal forma que, mientras para proceder no es necesario que el Ministerio Fiscal esté seguro de la prueba de la culpabilidad, para excluir el ejercicio de la acción penal, lo que condiciona negativamente (...) la punibilidad, deberá constar inequívocamente ${ }^{95}$.

acusación de una persona jurídica, aun cuando finalmente no llegase a ser condenada. Sobre las ventajas e inconvenientes de introducir el principio de oportunidad en los procesos penales frente a las personas jurídicas, me permito remitirme a la siguiente obra de mi autoría: NEIRA PENA, A. M ${ }^{\mathrm{a}}$.: La instrucción de los procesos penales frente a las personas jurídicas, Tirant Lo Blanch, Valencia, 2017, pp.53-102.

95 GÓMEZ ORBANEJA, E.: Comentarios a la Ley de Enjuiciamiento Criminal, Tomo II, Vol. 1, Bosch, Barcelona, 1951, pp. 515-517. 
Resulta ilustrativo de la idea que se acaba de exponer, lo acontecido con la imputación de la entidad Deloitte en el denominado caso Bankia. Así pues, en un primer momento, el Juzgado Central de Instrucción número 4 decidió archivar las actuaciones penales frente a la empresa de auditoría, argumentando que, por la representación procesal de la misma, se habría aportado a la causa documentación que acreditaría sobradamente que la misma contaba con un "Manual de Compliance" respetuoso con los requisitos establecidos en el CP, así como con "suficientes herramientas, políticas $y$ protocolos, que componen el llamado "Sistema de Control de Calidad", adecuado para exigir al personal de la misma el cumplimiento de las normas profesionales, estableciendo medidas de vigilancia y control idóneas para evitar la comisión de ilícitos" $"$.

La referida resolución judicial podría hacer pensar que la aportación documental del programa de cumplimiento en la instrucción resulta suficiente para exonerar a la entidad de responsabilidad. Ahora bien, el referido auto de archivo fue recurrido y revocado por la Sala de lo Penal de la Audiencia Nacional, en una resolución en la que se argumenta que, a pesar de que consta en la causa que "la firma cuenta con un Control de Calidad Interno, y un Manual de Cumplimiento Normativo que comprende Políticas generales para todas las líneas de servicio, y se alega que existen Politicas de nivel 2 para la línea de auditoría", de acuerdo con el parecer de la Audiencia Nacional, "debe continuar vigente la acción penal y des-

96 AJCI núm. 4, de 11 de mayo de 2017. Otra de las cuestiones a las que alude el referido auto para sobreseer la causa en relación con la entidad Deloitte es que se trata de "una Sociedad Profesional, regida por la Ley $2 / 2007$, de 15 de marzo, de forma y manera que la actuación profesional de los Socios que la integran se rige, por mandato legal, por los principios de absoluta autonomía e independencia de criterio en el desempeño de su trabajo de auditoría". Por lo tanto, de acuerdo con esta interpretación, la responsabilidad por la firma del informe de auditoría recaería, única y exclusivamente, sobre el socio, y no sobre la sociedad a la que este pertenece. 
lindar en otro momento procesal, si se han adoptado todas las políticas de prevención de riesgos penales para la exención de responsabilidad criminal" ${ }^{\prime 97}$. Con este devenir de los hechos, no es posible saber cuál habría sido el parecer del Tribunal, si Deloitte, además de aportar documentalmente su programa, hubiese presentado al juez instructor un informe pericial avalando su gestión en el caso Bankia, así como la idoneidad y eficacia de sus medidas de prevención de riesgos penales para prevenir los delitos que se le imputan, pero sí que parece razonable afirmar que, al menos, en tal supuesto, el juez de instrucción contaría con una base más sólida para sobreseer libremente la causa frente a la entidad auditora, por entender que esta aparece indudablemente exenta de responsabilidad penal (arts. $637.3^{\circ}$ y 640 LECrim).

Terminada la fase de instrucción, el juez penal, con base en el art. 729.2 LECrim, todavía podría intervenir en la actividad probatoria, por ejemplo, acordando de oficio una prueba pericial, cuando la considerase necesaria para comprobar algún hecho de los descritos en los escritos de calificación. Ahora bien, tal y como señala Vegas Torres, es preciso admitir que, dado el prácticamente nulo uso que los tribunales penales hacen de la facultad de acordar pruebas de oficio, los informes periciales se hacen presentes en la fase de juicio oral siempre por iniciativa de las partes, bien incorporando como prueba los aportados en fase de instrucción, bien encargándolos ex novo ${ }^{98}$.

Pues bien, centrando el análisis en la aportación ex novo de informes periciales de parte, esto es, pericias no presentadas en la instrucción que se pretenden hacer valer como prueba en el proceso, es preciso determinar cuál es el momento preclusivo para su proposición y aportación.

La LECrim establece que los informes periciales de parte deben de proponerse, como el resto de las pruebas, en

97 AAN (Sala de lo Penal, Sección 3a) núm. 351/2017, de 15 septiembre (JUR 2017/246099), F. J. $3^{\circ}$. 
el escrito de calificación, tratándose de un juicio ordinario (art. 656 LECrim), término que se amplía hasta el inicio de las sesiones del juicio oral, tratándose de un juicio abreviado (art. 785.1 II LECrim). En este último caso, para evitar causarle indefensión a la contraparte, sería conveniente que el dictamen se aportase con cierta antelación. En ese sentido, de lege ferenda, se propone exigir su aportación al menos cinco días hábiles antes del juicio oral, por analogía con lo establecido en el art. 338.2.I LECiv, sobre la aportación de los dictámenes cuya necesidad o utilidad venga suscitada por la contestación a la demanda o por lo alegado en la audiencia previa del procedimiento civil ordinario. Sin embargo, la LECrim nada dispone a este respecto.

En caso de que el informe se presente el mismo día de la vista o sin apenas antelación, la contraparte podrá pedir una suspensión y aplazamiento para instruirse del contenido de dicho informe, así como para presentar una pericial alternativa $^{99}$. Si tal aplazamiento no se concede, sufriría el principio de contradicción y, en caso de producirse indefensión o de vulnerarse la tutela judicial efectiva, se podría incluso provocar la nulidad del juicio ${ }^{100}$.

98 VEGAS TORRES, J.: "Análisis sobre la prueba pericial...”, cit., p. 70.

99 Según SAIZ DÍAZ, C.: "La prueba pericial de contenido económico...”, cit., p. 25, la práctica de presentar estas pericias extemporáneamente resulta criticable, sobre todo en aquellos casos en que no obedece a causas objetivas que hayan impedido su presentación anterior, sino a una estrategia procesal dirigida a limitar la contradicción o a provocar dilaciones indebidas en el procedimiento, en cuyo caso, tales pruebas debieran de ser inadmitidas.

100 En la STS (Sala 2a, Sección $1^{\text {a }}$ ) núm. 475/2015, de 30 de junio (RJ 2015\3223) se entendió que la indefensión provocada por la aportación tardía del peritaje por la defensa debía conducir a la anulación de la sentencia absolutoria, debiendo retrotraerse las actuaciones para darle a la acusación la oportunidad de examinar y contradecir la nueva prueba pericial de descargo. En este sentido, en la referida resolución se argumenta que "La preservación del derecho del denunciado a un proceso sin dilaciones indebidas, que constituye la fundamentación última de la denegación de la suspensión, no constituye en el caso actual una 
El Tribunal Supremo ha establecido unos criterios para determinar cuando la denegación de la suspensión ante la formulación de una prueba nueva en el propio acto del juicio oral puede suponer una vulneración del derecho a la tutela judicial efectiva. Tales criterios son: $1^{\circ}$ ) que la prueba resulte determinante de la resolución del caso y que, por su naturaleza o complejidad, exija un análisis que no pueda realizarse en el propio acto, o bien que requiera la eventual propuesta de prueba contradictoria; $2^{\circ}$ ) que no haya concurrido negligencia de la propia parte recurrente, la cual ha de haber solicitado oportuna y motivadamente el aplazamiento de la vista; $3^{\circ}$ ) que la decisión de denegar la suspensión revele una clara desproporción entre los fines que preserva (principalmente, el evitar dilaciones indebidas) y los intereses que sacrifica (la tutela judicial efectiva y el derecho de defensa de quien solicita el aplazamiento), sea por su rigorismo, sea por su formalismo excesivo o por cualquier otra razón ${ }^{101}$.

Pues bien, tomando en la debida consideración los criterios determinados por el Tribunal Supremo, hay que advertir que los dictámenes periciales "desempeñan en muchos casos un papel muy relevante en la prueba de los hechos en que se basa la acusación o en la de los alegados por la defensa, siendo determinantes con frecuencia del sentido condenatorio o absolutorio de la sentencia penal" 102 . Además, concretamente las periciales de naturaleza económica suelen ser complejas, lo que puede dificultar su examen en el mismo acto de la vista. Hay que tener en cuenta, así mismo, que normalmente

justificación suficiente y razonable, pues por una parte dicho derecho no resultaría gravemente alterado por una breve suspensión, y por otra se ha producido a costa de situar a la recurrente en una manifiesta situación de indefensión ante la presentación extemporánea de un complejo dictamen pericial, basado en una documentación contable que no obraba en la causa (las cuentas consolidadas del grupo) y que contradecía la prueba pericial debidamente realizada en la causa con la antelación suficiente (F. J. $3^{\circ}$ ).

101 STS (Sala 2a $2^{\text {a }}$ Sección $1^{\text {a }}$ ) núm. 475/2015, de 30 de junio (RJ 2015\3223), F. J. $4^{\circ}$. 
requerirán la presentación de una pericial contradictoria, dado que el parecer técnico del perito económico difícilmente podrá rebatirse exitosamente con alegaciones jurídicas o declaraciones testificales. Y, no sólo eso, sino que, además, muchas veces la pericial económica resultará absolutamente determinante del resultado del pleito, como suele ocurrir, señaladamente, en los delitos concursales (art. 261 CP), en ciertos delitos societarios (art. $290 \mathrm{CP}$ ) o en los delitos fiscales (art. $310 \mathrm{CP}$ ), consistentes, precisamente, en alteraciones o manipulaciones de la contabilidad. De ahí que se pueda afirmar que su presentación tardía puede causar indefensión a la contraparte.

\section{La valoración de la prueba pericial por el juez de instancia y posibilidad de impugnación}

La prueba pericial, al igual que el resto de las pruebas practicadas en el juicio, se valorará de acuerdo con la regla de libre valoración de la prueba (art. 741 LECrim). Por lo tanto, las conclusiones del perito en ningún caso vincularán al juzgador, que podrá apartarse de los resultados de la pericia, siempre que motive su parecer, ya poniendo en duda la fiabilidad y/o razonabilidad del informe pericial, ya realizando una valoración conjunta de las pruebas practicadas en juicio.

Según Flores PRADA "el juicio del tribunal no debe ser un juicio técnico-científico sino un juicio de credibilidad, que ha de medir tanto la cualificación y objetividad del experto, como la verosimilitud - coherencia interna, corrección, lógica, racionalidad y razonabilidad, argumentación- de datos, opiniones y conclusiones expuestas en el dictamen" ${ }^{103}$. Sobre esta cuestión, afirma VÁzquez Sotelo que el juez debe controlar el grado de aceptación de las conclusiones de los peritos, así como

102 VEGAS TORRES, J.: "Análisis sobre la prueba pericial...", cit., p. 64.

103 FLORES PRADA, I.: La prueba pericial de parte en el proceso civil, Tirant lo Blanch, Valencia, 2005, p. 343. 
la razonabilidad y fiabilidad de los procedimientos de análisis realizados, ya que, "si al perito toca resolver un problema científico, o una duda técnica, al juez corresponde resolver el problema del proceso, que es siempre un problema humano y de proyección social" 104 .

Son, por lo tanto, criterios relevantes que el juzgador tomará en consideración a la hora de valorar los dictámenes periciales, entre otros, la idoneidad del perito, considerando su formación y experiencia, la metodología empleada en la pericia y su aceptación por la comunidad científica, la fundamentación o razonamiento en que se sustenten las conclusiones del dictamen, la probabilidad con que tales conclusiones se afirmen, las hipótesis o explicaciones alternativas que puedan existir a las conclusiones alcanzadas por el perito, así como, por supuesto, la existencia de dictámenes periciales contradictorios o de otras pruebas que contradigan las conclusiones de la pericia.

Evidentemente, y enlazando con la problemática inicial planteada en relación con el choque de ciertos informes periciales económicos con el principio iura novit curia, cabe señalar que cuanto más difícil resulte el deslinde entre lo técnico y lo jurídico, más razonable será que el juez se separe de la interpretación realizada por el perito sobre los hechos analizados, en tanto que, en la determinación del derecho aplicable, el juez es soberano.

Así, por ejemplo, en relación con un ámbito de criminalidad absolutamente diverso del que es objeto de este trabajo, el Tribunal Constitucional señala que la apreciación de un médico sobre la capacidad cognitiva y volitiva de un encausado no prejuzga la cuestión jurídica sobre su impu-

104 VÁZQUEZ SOTELO, J. L.: Presunción de inocencia del imputado e íntima convicción del tribunal. Estudio sobre la utilización del imputado como fuente de prueba en el proceso penal español, Bosch, Barcelona, 1985 , pp. 470-479, esp. 478-479 
tabilidad o capacidad de culpabilidad, dado que estas son categorías jurídicas y no médicas, cuya apreciación, por lo tanto, es una cuestión de Derecho que no resulta en absoluto prejuzgada por la opinión de los peritos ${ }^{105}$.

Igualmente, cabe observar que, aunque el perito tributario pueda realizar un determinado cálculo de la cuota tributaria defraudada, el juez podría no estar de acuerdo con qué parte de esa cuota se ha dejado de ingresar dolosamente y qué montante encontraría justificación en una interpretación razonable de la norma tributaria, con lo que ambos profesionales podrían, legítimamente, alcanzar resultados numéricos distintos, diferencia que podría resultar determinante de la relevancia o irrelevancia penal de la conducta.

Del mismo modo, aunque el perito de compliance afirme que los mecanismos de control preordenados a evitar el delito perpetrado en el seno de una organización empresarial eran eficaces, el juez podría entender que, en el caso concreto, se incumplieron gravemente los deberes de control, debido, por ejemplo, al tiempo que tardó en detectarse la conducta criminal o, en su caso, argumentar que la entidad no contaba con una cultura de cumplimiento normativo suficientemente arraigada, en vista del desconocimiento mostrado por los empleados llamados como testigos en relación con los instrumentos de prevención.

En definitiva, hay que tener en cuenta que la perspectiva y alcance de la pericia y del juicio jurisdiccional es normalmente distinto y que, en lo relativo a las cuestiones jurídicas, el juez podrá imponer su criterio al del perito sin necesidad de hacer un extraordinario esfuerzo motivacional.

En cuanto a la posibilidad de recurrir la valoración judicial del informe pericial realizada por el juez, hay que tener en cuenta que, como regla general, tal juicio valorativo relativo a una prueba de carácter personal constituye una función

105 ATC núm. 343/1987, de 18 de marzo, F. J. 2º párrafo e). 
soberana del tribunal de instancia, solo revisable en casación cuando se aprecia una motivación irracional, absurda, ilógica o arbitraria ${ }^{106}$.

Mención especial merece el motivo de casación por infracción de ley, debido al error en la apreciación de la prueba, basado en documentos que obren en autos, que demuestran la equivocación del juzgador sin resultar contradichos por otros elementos probatorios (art. 849.2 ${ }^{\mathrm{a}}$ LECrim). Aunque la literalidad de la norma se refiere a pruebas de carácter documental, y no a pruebas personales, como lo son las periciales, excepcionalmente, se admite que la valoración incorrecta de un informe pericial puede ser válidamente aducida como motivo de casación por error en la apreciación de la prueba, para fundamentar, por esta vía, la pretensión de modificación del apartado fáctico de la sentencia impugnada. Ahora bien, ello sólo es posible en los casos en que el Tribunal haya estimado el dictamen o dictámenes coincidentes como base única de los hechos declarados probados, pero incorporándolos a dicha declaración de un modo incompleto, fragmentario, mutilado o contradictorio, de modo que se altere relevantemente su sentido originario o se alcancen conclusiones divergentes con las de los citados informes sin expresar las razones que las justifican ${ }^{107}$.

106 En este sentido, se pronuncian, entre otras muchas, la STS (Sala 2a , Sección $1^{\text {a }}$ ) núm. 192/2019, de 9 abril (RJ 2019\1338), F. J. $2^{\circ}$ y la STS (Sala $2^{a}$, Sección 1 ${ }^{\text {a }}$ ) núm. 704/2018, de 15 enero 2019 (Caso Terra Mítica) (RJ 2019\145). En esta última se indica que "salvo supuestos en que se constate irracionalidad o arbitrariedad, este cauce casacional no está destinado a suplantar la valoración por parte del Tribunal sentenciador de las pruebas apreciadas de manera directa, como las declaraciones testificales o las manifestaciones de los imputados o coimputados, así como los dictámenes periciales, ni realizar un nuevo análisis crítico del conjunto de la prueba practicada para sustituir la valoración del Tribunal sentenciador por la del recurrente o por la de esta Sala, siempre que el Tribunal de Instancia haya dispuesto de prueba de cargo suficiente y válida, y la haya valorado razonablemente" (F. J. $3^{\circ}$ ).

107 Entre otras, STS (Sala 2a , Sección 1 ${ }^{\text {a) }}$ núm. 259/2016, de 1 de abril (RJ 2016\1452), F. J. $5^{\circ}$ y STS (Sala $2^{\text {a }}$, Sección $1^{\text {a }}$ ) núm. 704/2018, de 15 enero 2019 (Caso Terra Mítica) (RJ 2019\145), F. J. $12^{\circ}$ 


\section{Conclusiones}

1. En la actualidad, la criminalidad económica ha alcanzado elevadas cotas de complejidad y sofisticación. La posición social y formación intelectual del delincuente de cuello blanco, puestas a disposición de refinadas tramas delictivas, han provocado una tecnificación de este tipo de delincuencia, cuya investigación y enjuiciamiento demanda conocimientos especializados de los cuales, en muchas ocasiones, el juzgador carece. De ahí, la necesidad de contar con peritos capaces de desentrañar e interpretar la información contenida en documentos de carácter técnico, económico o contable, para acreditar si una conducta ilícita ha tenido lugar o no.

2. De la mano de la evolución de la criminalidad económica, avanzan también las diversas modalidades periciales. En este sentido, a día de hoy, dentro del concepto genérico de pericial económica es posible distinguir una heterogénea lista de actuaciones, que van desde las clásicas operaciones de análisis contable y auditoría de cuentas, pasando por periciales tributarias, valoración de empresas o bienes intangibles, hasta llegar, de la mano de la responsabilidad penal de las personas jurídicas, a la novedosa figura del perito de compliance.

3. La labor del perito de compliance consiste en determinar, a través de la evaluación de las políticas internas de una organización, así como de la aplicación e interpretación de ciertas normas técnicas en la materia, si una persona jurídica cuenta, o contaba en un determinado momento temporal, con medidas de prevención delictiva eficaces. Pues bien, establecida la idoneidad de esta pericia como forma de integrar con conocimiento experto los elementos constitutivos de la responsabilidad penal de las empresas, se plantean una serie de problemas que la legislación no resuelve, de los cuales dos resultan, a mi juicio, esenciales. Primeramente, cuál ha de ser el objeto y alcance de esta pericia y cómo debe de con- 
jugarse con el principio iura novit curia. Y, en segundo lugar, cuál ha de ser la formación requerida para este profesional.

4. La formación del perito económico carece de una regulación clara. Existen una multiplicidad de profesionales que podrían desarrollar esta actividad procesal, en su mayor parte del ámbito privado, a lo que se suma la existencia de diversos colegios profesionales y la ausencia de un registro único de expertos que sirva de auxilio a la Administración de Justicia en este ámbito. En el caso de la pericial de complian$c e$, la situación es todavía más desoladora, dado que no existe ningún tipo de formación reglada para este tipo de profesional, lo que puede favorecer el intrusismo y restar credibilidad a la labor de los expertos en la materia.

5. El perito económico, como cualquier perito, viene llamado al proceso para dar su opinión técnica sobre ciertos hechos, debiendo abstenerse de realizar valoraciones o juicios jurídicos. Ahora bien, ciertas pruebas periciales, como las tributarias o de compliance, precisan del conocimiento y uso de normas jurídicas en su desarrollo. Así pues, el perito podrá emplear tales normas, si bien el juez, en lo relativo a la determinación, aplicación e interpretación del Derecho, actuará soberanamente, pudiendo hacer valer su parecer sobre el del experto a la hora de valorar la pericia.

6. El hecho de que los peritos económicos pertenezcan, normalmente, al ámbito privado, puede hacer dudar de su imparcialidad. Este riesgo se agudiza cuando los peritos son nombrados por una de las partes y, en atención a las relaciones comerciales del perito con la parte o su contacto previo y extraprocesal con los hechos, pudiera considerarse que aquel tiene interés en que la causa se resuelva en un determinado sentido. Por su parte, en el caso de los funcionarios de la Agencia Tributaria, los problemas de imparcialidad se entienden superados, precisamente, por su condición de funcionarios públicos, lo que puede ponerse en duda atendiendo al modo en que tales profesionales son designados 
para actuar como peritos y, sobre todo, a su pertenencia a la Administración Tributaria, habitualmente personada como acusación particular en los procesos penales por delitos contra la Hacienda Pública.

7. Por último, hay que tener en cuenta que, cuando son las partes las que aportan los informes periciales, podrán hacerlo ya en instrucción, pudiendo resultar las pericias determinantes de la decisión de archivar las actuaciones o de abrir el juicio oral. Esta posibilidad resulta clave para la defensa que, a través de un informe pericial que evidencie la atipicidad de la conducta o la irresponsabilidad del investigado, puede evitar la denominada pena de banquillo, la cual puede resultar letal para determinadas empresas en las que el valor reputacional resulta ser un activo esencial y, en ocasiones, incluso, clave para su supervivencia en el mercado.

\section{Bibliografía}

AA.VV.: Alonso Alaya, M.; Picazo González, P.; Malón Muñoz, A. (coords.) Memento experto. Perito Judicial. Francis Lefevbre, Madrid, 2017.

BALAGUÉ DOMÉNECH, J. C.: La prueba pericial contable en las jurisdicciones civil, penal, contencioso-administrativa y laboral, 5a ed., Bosch, Madrid, 2007.

BALAGUÉ DOMÉNECH, J. C.: La prueba pericial contable en las jurisdicciones civil, penal, contencioso-administrativa y laboral, $7^{\mathrm{a}}$ ed., Bosch, Madrid, 2018.

CÁMARA RUIZ, J.: "La prueba pericial contable en el proceso civil y penal", en AA.VV.: Pérez-Cruz Martín, A-J; Ferreiro Baamonde, X. (dirs.); Neira Pena, A. M ${ }^{\mathrm{a}}$ (coord.) Los retos del Poder Judicial ante la sociedad globalizada. Actas del IV Congreso Gallego de Derecho Procesal (I Internacional), Servizo de Publicacións da Universidade da Coruña, A Coruña, 2012, pp. 51-72. 
CASTELLS LLAVINÉS, J.: "Dictámenes periciales sobre aspectos económicos. Metodología y ámbito", Diario La Ley, núm. 8119, 4 de julio de 2013, pp. 1-4.

COCA VILA, I.: "¿Programas de cumplimiento como forma de autorregulación regulada?", en AA.VV.: J-M, Silva Sánchez (Dir.), R. Montaner Fernández (Coord.) Criminalidad de empresa y compliance. Prevención y reacciones corporativas, Atelier, Barcelona, 2013, pp. 43-76.

DE LA OLIVA SANTOS, A.; DÍEZ-PICAZO GIMÉNEZ, I.: Derecho Procesal Civil. El proceso de declaración, $3^{\mathrm{a}}$ ed., Centro de Estudios Ramón Areces S.A., Madrid, 2004.

FLORES PRADA, I.: La prueba pericial de parte en el proceso civil, Tirant lo Blanch, Valencia, 2005.

GALLEGO SOLER, J-I.: "Criminal compliance y proceso penal: reflexiones iniciales” en AA. VV., Mir Puig, S.; Corcoy Bidasolo, M.; Gómez Martín, V (dirs.); Hortal Ibarra, J. C.; Valiente Ibáñez, V. (coords.) Responsabilidad de la empresa y compliance. Programas de prevención, detección y reacción penal, B de F, Montevideo-Buenos Aires, 2014, pp. 195-229.

GAMO YAGÜE, R.: "Colaboración de la Agencia Estatal de Administración Tributaria con los órganos jurisdiccionales", https://www.fiscal.es/fiscal/PA_WebApp_ SGNTJ_NFIS/descarga/ponencia $\% 20$ escrita $\% 20$ Sra\%20Gamo.pdf?idFile $=4 a 5 a 63 f c-d f e 5-47$ ad-980290936202c254, pp. 1-26.

GASCÓN INCHAUSTI, F.: Proceso penal y persona jurídi$c a$, Marcial Pons, Madrid/Barcelona/Buenos Aires/ Sao Paulo, 2012.

GIMENO BEVIÁ, J.: Compliance y proceso penal. El proceso penal de las personas jurídicas, Aranzadi, Navarra, 2016. GIMENO SENDRA, V.: Derecho Procesal Civil, $4^{\circ}$ ed., Colex, Madrid, 2012. 
GÓMEZ ORBANEJA, E.: Comentarios a la Ley de Enjuiciamiento Criminal, Tomo II, Vol. 1, Bosch, Barcelona, 1951.

GÓMEZ ORBANEJA, E.; HERCE QUEMADA, V.: Derecho procesal penal, $10^{\mathrm{a}}$ ed., Artes Gráficas y Ediciones, Madrid, 1986.

GÓMEZ-JARA DÍEZ, C.: "La culpabilidad de la persona jurídica” en M. Bajo Fernández; B. J. Feijoo Sánchez; C. Gómez-Jara Díez, Tratado de responsabilidad penal de las personas jurídicas. 2. ${ }^{\mathrm{a}}$ ed. Adaptado a la Ley 1/2105, de 30 de marzo, por la que se modifica el Código Penal, Aranzadi, Navarra, 2016, pp. 143-219.

GOÑI SEIN, J. L.: "Programas de cumplimiento empresarial (compliance programs): aspectos laborales", en AA.VV.: S. Mir Puig; M. Corcoy Bidasolo; V. Gómez Martín (dirs.); J. C. Hortal Ibarra; V. Valiente Ibáñez (coords.) Responsabilidad de la empresa y compliance. Programas de prevención, detección y reacción penal, B de F, Montevideo-Buenos Aires, 2014, pp. 367-419

GUASP DELGADO, J.: Derecho Procesal Civil, Instituto de Estudios Políticos, Madrid, 1962.

JIMÉNEZ VILLAREJO, C.: "La prueba pericial en los delitos económicos (con particular referencia a la intervención de los Inspectores de Finanzas del Estado)", Jueces para la democracia, núm. 31, 1998, pp. 59-67.

LÓPEZ-MUÑIZ GOÑI, M.: La prueba pericial. Guía práctica y jurisprudencia, Colex, Madrid, 2008.

MAGRO SERVET, V.: "Hacia la creación del registro de expertos en programas de compliance", Diario La Ley, núm. 9362, 2019, pp. 1-7.

MAGRO SERVET, V.: "Viabilidad de la pericial de compliance para validar la suficiencia del programa de cumplimiento normativo por las personas jurídicas", Diario La Ley, núm. 9337, 2019, pp. 1-7

MARCHENA GÓMEZ, M.: "De peritos, cuasiperitos y pseudoperitos”, Poder Judicial, núm. 39, 1995, pp. 233-252. 
MARTÍNEZ-BUJÁN PÉREZ, C.: Derecho penal económico, Iustel, Madrid, 2012.

NEIRA PENA, A. M ${ }^{\mathrm{a}} .:$ La defensa penal de la persona jurídica. Representante defensivo, rebeldía, conformidad, compliance como objeto de prueba, Aranzadi, Navarra, 2018.

NEIRA PENA, A. M ${ }^{\mathrm{a}}$. : La instrucción de los procesos penales frente a las personas jurídicas, Tirant Lo Blanch, Valencia, 2017.

NIETO MARTÍN, A.: "Fundamento y estructura de los programas de cumplimiento normativo", en Nieto Martín, A. (Dir.) Manual de cumplimiento penal en la empresa, Tirant lo Blanch, Barcelona, 2015, pp. 111-134.

SAIZ DÍAZ, C.: "La prueba pericial de contenido económico en el proceso penal", Revista del REFOR, núm. 9-10, 2004, pp. 23-29

SÁNCHEZ ULLED, E. J.: "Estrategias de investigación en los delitos económicos complejos. La criminalidad económica organizada" en M. A. Gimeno Jubero (Dir.) Estudios de Derecho Judicial, núm. 72, ejemplar dedicado a Derecho Penal económico, CGPJ, Madrid, 2006, pp. 11-48.

VÁZQUEZ SOTELO, J. L.: Presunción de inocencia del imputado e íntima convicción del tribunal. Estudio sobre la utilización del imputado como fuente de prueba en el proceso penal español, Bosch, Barcelona, 1985.

VEGAS TORRES, J.: "Análisis sobre la prueba pericial en la Ley de Enjuiciamiento Civil y en el proceso penal español", en LAGUNA SÁNCHEZ, P., et al. La prueba pericial económica en el ámbito procesal español, Universidad Rey Juan Carlos, Madrid, pp. 51-71, disponible en https://eciencia.urjc.es/handle/10115/12106

WRAY, C. A.; HUR, R. K.: "The power of the corporate charging decisions over corporate conduct", Yale Law Journal Pocket Part, núm. 116, 2007, pp. 306 -311. 